\title{
Incident Analysis Report: B696 MOVER Event, August 19, 2004
}

D. Rex Beach, ${ }^{1}$ Stephen Carr, ${ }^{1}$ Brian Anderson, ${ }^{1}$ James Lewis, ${ }^{1}$ James Merrigan, ${ }^{1}$ John Richards, ${ }^{1}$ Timothy Smith, ${ }^{1}$ and Richard Scott ${ }^{2}$

\section{Report Serial Number: 0514}

\section{November 11, 2004, Rev. 1}

U.S. Department of Enargy

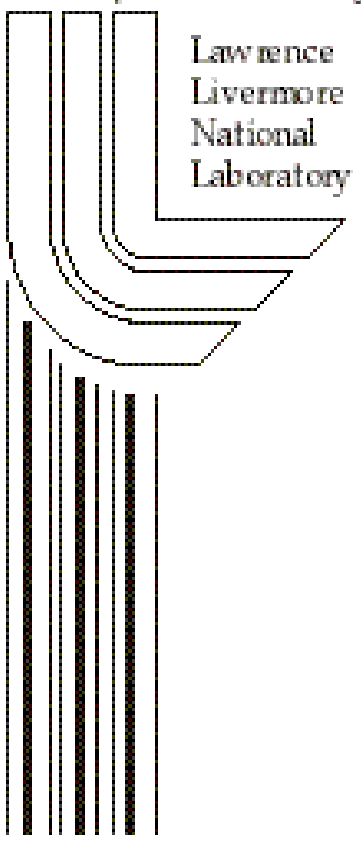

\author{
${ }^{1}$ Lawrence Livermore National Laboratory \\ ${ }^{2}$ Livermore Site Office, U.S. Department of Energy
}




\section{DISCLAIMER}

This document was prepared as an account of work sponsored by an agency of the United States Government. Neither the United States Government nor the University of California nor any of their employees, makes any warranty, express or implied, or assumes any legal liability or responsibility for the accuracy, completeness, or usefulness of any information, apparatus, product, or process disclosed, or represents that its use would not infringe privately owned rights. Reference herein to any specific commercial product, process, or service by trade name, trademark, manufacturer, or otherwise, does not necessarily constitute or imply its endorsement, recommendation, or favoring by the United States Government or the University of California. The views and opinions of authors expressed herein do not necessarily state or reflect those of the United States Government or the University of California, and shall not be used for advertising or product endorsement purposes.

This work performed under the auspices of the U.S. Department of Energy by University of California Lawrence Livermore National Laboratory under Contract W-7405-ENG-48 


\section{Incident Analysis Report: B696 MOVER Event, August 19, 2004}

November 11, 2004, Rev. 1

1). $\operatorname{les} 0$ Seac

D. Rex Beach

Deputy Associate Director

SEP Directorate

Team Lead

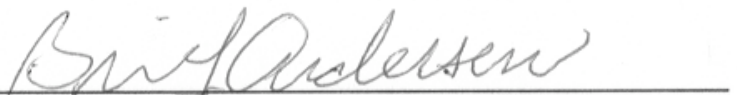

Brian Anderson

New Technologies Engineering Division

Engineering Directorate
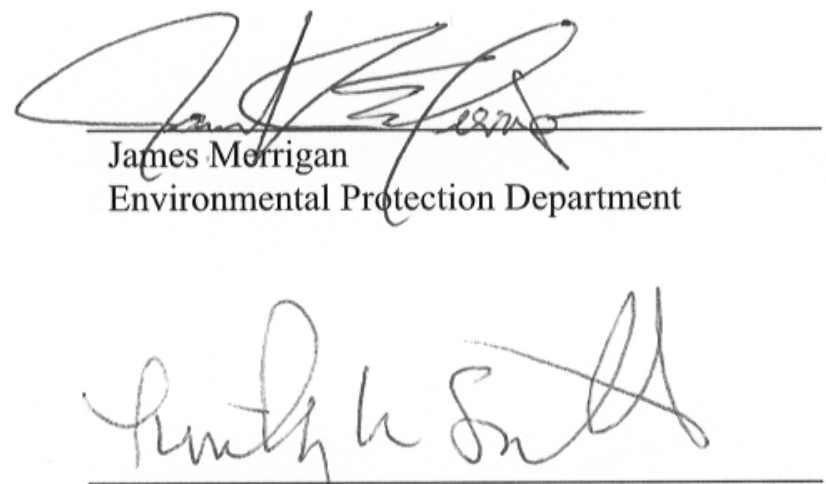

Timothy Smith

ES\&H Team 1

Hazards Control Department

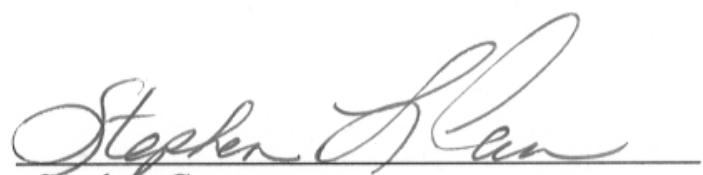

Stephen Carr

Department Head

Hazards Control Department

Team Lead

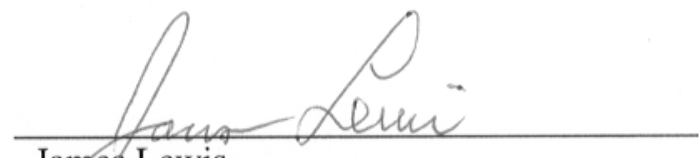

Janes Lewis

ES\&H Team 1

Hazards Control Department

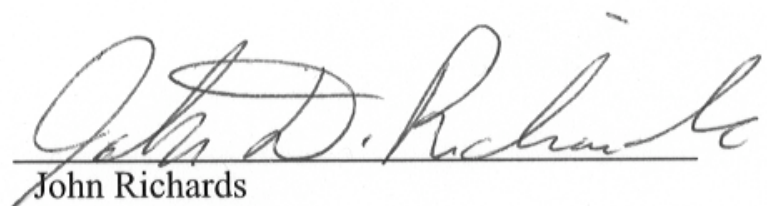

Emergency Programs

Hazards Control Department

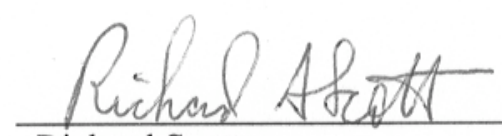

Richard Scott

Livermore Site Office

U.S. Department of Energy 


\section{Table of Contents}

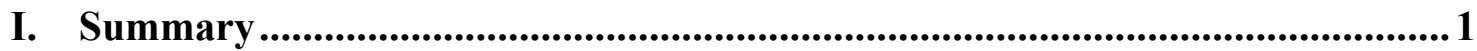

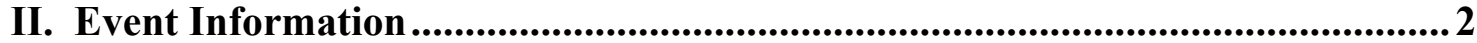

III. Project Background ..................................................................................3

IV. Event Description............................................................................................ 7

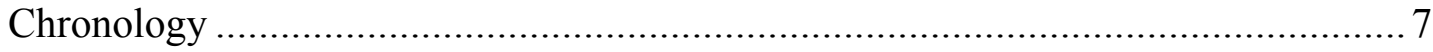

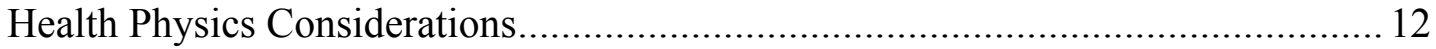

Potential Sources of Airborne Radioactivity from Glovebox Operations................ 16

Early Warning and Actions Taken to Address Airborne Radioactivity Concerns .... 17

Current Evaluation of Dose Consequences ................................................... 21

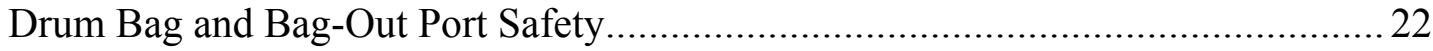

V. Committee Comments ...................................................................................... 28

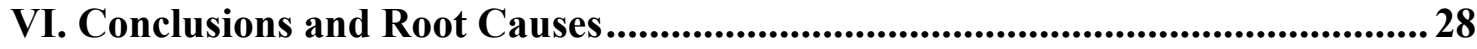

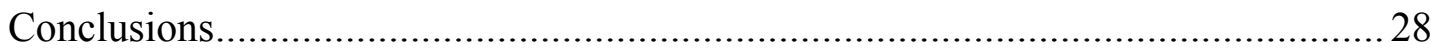

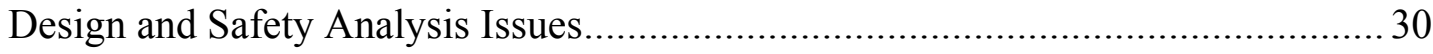

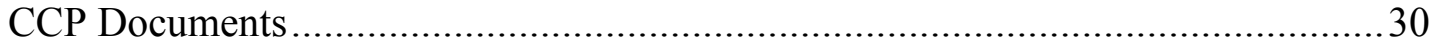

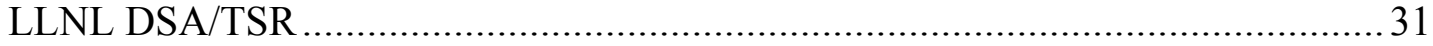

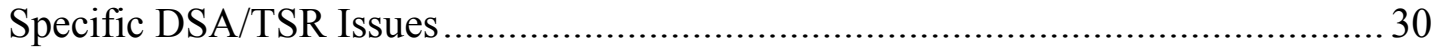

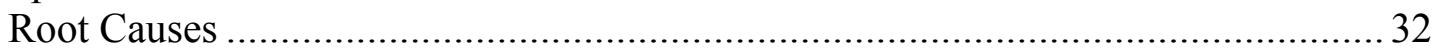

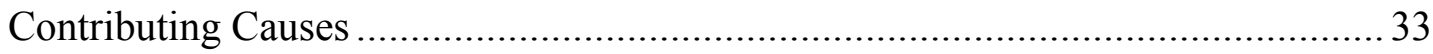

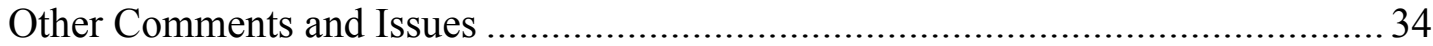

VIII. Judgments of Need ............................................................................ 35

Appendix A: Facility Description ............................................................................ 37

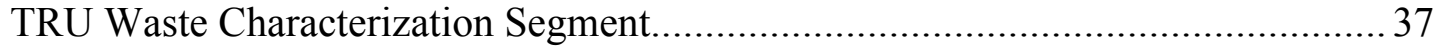

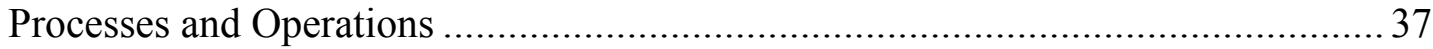

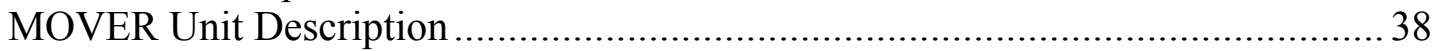

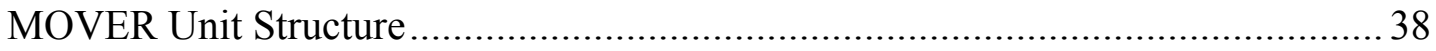

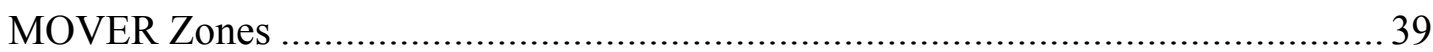

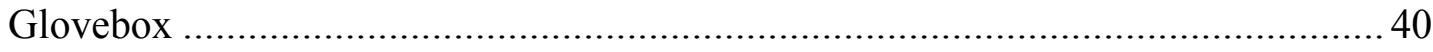

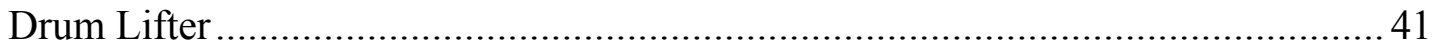

Glovebox Equipment Airlock ......................................................................... 41

HEPA Filtration System ............................................................................. 42

Other Unit Components.............................................................................. 43

Heating, Ventilating, and Air Conditioning (HVAC) System............................. 44

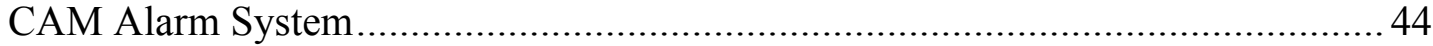

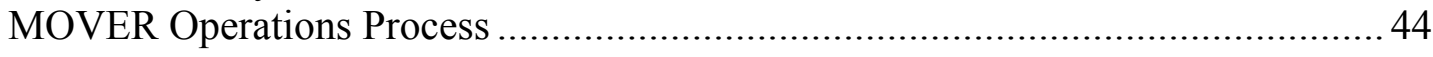

Appendix B: Gross Alpha Measurements from the B695 MOVER Unit............... 46 


\section{List of Figures}

Figure 1. Location of DWTF complex............................................................. 4

Figure 2. Layout of DWTF areas, showing location of the MOVER ....................... 5

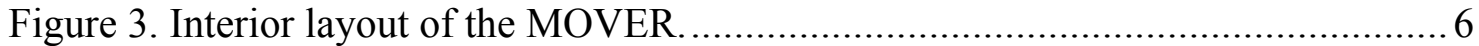

Figure 4. Event timeline. ............................................................................... 8

Figure 5. Air sample data. .............................................................................. 15

Figure 6. MOVER working and bag-change configuration. ................................... 23

Figure 7. LLNL Plutonium Facility working and bag-change configuration ...............2 24

Figure 8. Photo of MOVER configuration, August 19, 2004 ............................... 25 


\section{Acronyms}

\begin{tabular}{|c|c|}
\hline ANL & Argonne National Laboratory \\
\hline ASME & American Society of Mechanical Engineers \\
\hline B695 & Building 695 \\
\hline B696S & Building 696 Solid Waste Processing Area \\
\hline CAM & Continuous Air Monitor \\
\hline $\mathrm{CCP}$ & Central Characterization Project (Washington TRU Solutions) \\
\hline $\mathrm{CCs}$ & contributing causes \\
\hline $\mathrm{CDE}$ & Committed Dose Equivalent \\
\hline CEDE & Committed Effective Dose Equivalent \\
\hline cpm & counts per minute \\
\hline $\mathrm{DAC}$ & derived air concentration \\
\hline DAD & Deputy Associate Director \\
\hline dpm & disintegrations per minute \\
\hline DOT & U.S. Department of Transportation \\
\hline DSA/TSRs & Documented Safety Analysis/Technical Safety Requirements \\
\hline DWTF & Decontamination and Waste Treatment Facility \\
\hline EAL & Emergency Action Level \\
\hline EPD & Environmental Protection Department \\
\hline EPHA & Emergency Planning Hazard Assessment \\
\hline FPOC & Facility Point of Contact \\
\hline FAS & fixed air samplers \\
\hline $\mathrm{H} \& \mathrm{ST}$ & Health and Safety Technician \\
\hline $\mathrm{HCD}$ & Hazards Control Department \\
\hline HENC & High-Efficiency Passive Neutron Counter \\
\hline HEPA & high-efficiency particulate air \\
\hline HP & Health Physicist \\
\hline HP DAP & Health Physics Discipline Action Plan \\
\hline HQ & DOE/EM Headquarters \\
\hline HSGS & Headspace gas sampling \\
\hline HSGS-II & Headspace gas sampling system number II \\
\hline HVAC & heating, ventilating, and air conditioning (system) \\
\hline LANL & Los Alamos National Laboratory \\
\hline LEDO & Laboratory Emergency Duty Officer \\
\hline LLNL & Lawrence Livermore National Laboratory \\
\hline LTA & less-than-adequate \\
\hline MAR & Material at Risk \\
\hline MOVER & Mobile Visual Examination and Repackaging Unit \\
\hline IA & Incident Analysis \\
\hline IWS & Integration Worksheet (LLNL) \\
\hline ORR & Operational Readiness Review \\
\hline $\mathrm{PE} \mathrm{Ci}$ & plutonium-equivalent curie \\
\hline PLC & programmable logic controller \\
\hline PPE & personal protective equipment \\
\hline
\end{tabular}




$\begin{array}{ll}\text { RCMM } & \text { Root-Cause MiniMORT (process) } \\ \text { RHWM } & \text { Radioactive and Hazardous Waste Management Division } \\ \text { RML } & \text { Radiation Measurements Laboratory } \\ \text { RSS } & \text { Radiation Safety Section } \\ \text { RTR-II } & \text { Real-Time Radiography System Number II unit } \\ \text { SAD } & \text { Safety Analysis Document } \\ \text { SEP } & \text { Safety and Environmental Protection (Directorate) } \\ \text { SME } & \text { subject-matter expert } \\ \text { TRU } & \text { transuranic } \\ \text { TRUPACT-II } & \text { Transuranic Package Transporter Model II } \\ \text { TRUW } & \text { TRU waste } \\ \text { TWLP } & \text { Transuranic Waste Legacy Project } \\ \text { UC } & \text { University of California } \\ \text { VE } & \text { visual examination } \\ \text { WAC } & \text { Waste Acceptance Criteria } \\ \text { WIPP } & \text { Waste Isolation Pilot Plant } \\ \text { WTS } & \text { Washington TRU Solutions }\end{array}$




\section{Incident Analysis Report: B696 MOVER Event, August 19, 2004}

\section{Summary}

Report Date: November 11, 2004, Rev. $1 \quad$ Report Serial Number: 0514

\begin{tabular}{|c|c|c|c|}
\hline \multicolumn{4}{|c|}{ 1. SHORT DESCRIPTION: } \\
\hline \multicolumn{4}{|c|}{ Uptake of radioactive contamination by personnel working in an LLNL controlled facility. } \\
\hline 2. TYPE: & 3. DATE: & 4. TIME: & 5. LOCATION: \\
\hline $\begin{array}{l}\text { Incident Analysis } \\
\text { (IA) Committee }\end{array}$ & 8/19/04 & $1055 \mathrm{hrs}$ & $\begin{array}{l}\text { Mobile Visualization Examination and } \\
\text { Repackaging (MOVER) located at B696. }\end{array}$ \\
\hline \multicolumn{2}{|c|}{ 6. DEPARTMENTS INVOLVED: } & \multicolumn{2}{|c|}{ 7. INJURY/ILLNESS: } \\
\hline \multicolumn{2}{|c|}{$\begin{array}{l}\text { Environmental Protection } \\
\text { Department }\end{array}$} & \multicolumn{2}{|c|}{ Under investigation } \\
\hline \multicolumn{4}{|c|}{ Hazards Control Department } \\
\hline \multicolumn{2}{|c|}{ 8. HAZARDOUS MATERIALS: } & \multicolumn{2}{|c|}{ 9. PROPERTY DAMAGE: } \\
\hline \multicolumn{2}{|l|}{ Transuranic } & \multicolumn{2}{|l|}{ None } \\
\hline
\end{tabular}




\section{Event Information}

On August 19, 2004, three operators [employees of Washington TRU Solutions Central Characterization Project (CCP)] and one Health and Safety Technician [(H\&ST), an employee of the University of California (UC)] were working in the mobile characterization unit, known as the Mobile Visual Examination and Repackaging Unit (MOVER). The unit, which was located in the Decontamination and Waste Treatment Facility (DWTF) Yard, uses a glovebox to repackage Transuranic (TRU) drums. Work was in progress on the last set of drums to be repackaged.

Work had been completed on a TRU drum that was on its way out of the unit. Work had begun on a 0.6-plutonium-equivalent curie (PE Ci) TRU container. During the bag-in process for the 0.6-PE Ci container, operators encountered contamination measuring 6,000 counts per minute $(\mathrm{cpm})$, or approximately 12,000 disintegrations per minute $(\mathrm{dpm})$ on the exposed area of the drum port. The operators decontaminated the exposed, contaminated area of the drum port, and this exposed area was swiped again. The area was declared clean. During bag-out of the previous drum, operators noticed that the retaining band was not tightened optimally; therefore, the retaining band was replaced with a new one on this drum. The three operators and LLNL H\&ST were wearing respirators, as required by CCP Procedure CCP-TP-042 and by LLNL Integration Worksheet (IWS) 11359.

Operators were cleared to remove respirators once the area was verified as clean. An LLNL operator-in-training (Operator 4) had also entered the MOVER to assist in glovebox work. As the operators commenced opening and sorting waste parcels, the H\&ST checked the Continuous Air Monitor (CAM) and observed that the readout of the CAM had risen. The CAM alarm sounded shortly thereafter.

When the CAM alarm sounded, all personnel stopped work and immediately exited the glovebox area into an airlock, in accordance with CCP Procedure CCP-HSP-002. A full-body contamination frisk was conducted and cleared the personnel present to exit the MOVER. No contamination was noted on worker's clothing or skin (lab coats were not monitored at this time). Nasal swipes were taken. The H\&ST re-entered the room and assessed contamination, which was located in four areas. Four nasal swabs were positive, and one was negative. Lung counts that were subsequently taken were negative. 


\section{Project Background}

LLNL's Transuranic (TRU) Waste Legacy Project (TWLP) activities are being conducted in two temporary locations, collectively known as the TRU Waste Segments (TRUW Segments) of the Decontamination and Waste Treatment Facility (DWTF), located west of Building 695 (B695) and the Building 696 Solid Waste Processing Area (B696S). The DWTF complex is located in the northeastern quadrant of the LLNL Livermore site, as shown in Figure 1. Figure 2 shows the layout of DWTF areas, including the TRU waste characterization segment, the Transuranic Package Transporter Model II (TRUPACT-II) loading segment, and the location of the MOVER within the TRU waste characterization segment. Figure 3 shows the interior layout of the MOVER. These facilities are managed and operated by the Radioactive and Hazardous Waste Management (RHWM) Division of the Environmental Protection Department (EPD) to store and treat regulated wastes generated at LLNL. Appendix A provides a more detailed description of the MOVER.

The mission of the TWLP that is performed in the TRUW Segments is to characterize LLNL RHWM Division's TRU waste, repackage it as necessary, and load the waste drums into TRUPACT-II casks for offsite shipment. The waste must meet both U.S. Department of Transportation (DOT) shipping requirements and the Waste Acceptance Criteria (WAC) for the receiving facility, which will be the Waste Isolation Pilot Plant (WIPP). Characterizing and shipping TRU waste from the RHWM inventory to an off-site location allows RHWM to accommodate newly generated TRU waste drums from LLNL facilities and provides for interim storage until the drums can be shipped off site. 


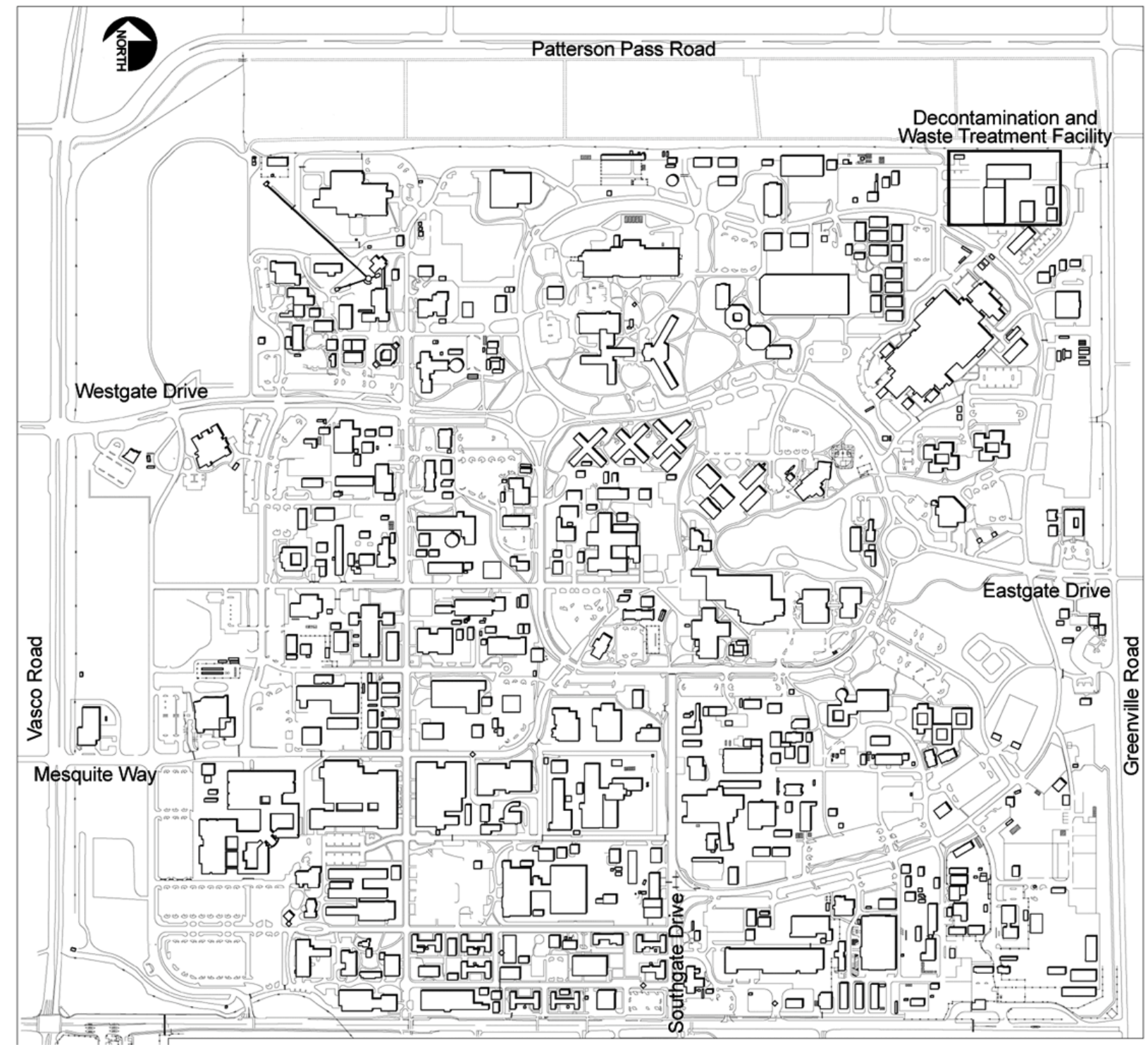

Figure 1. Location of DWTF complex in the northeast corner of LLNL's Livermore Site. 


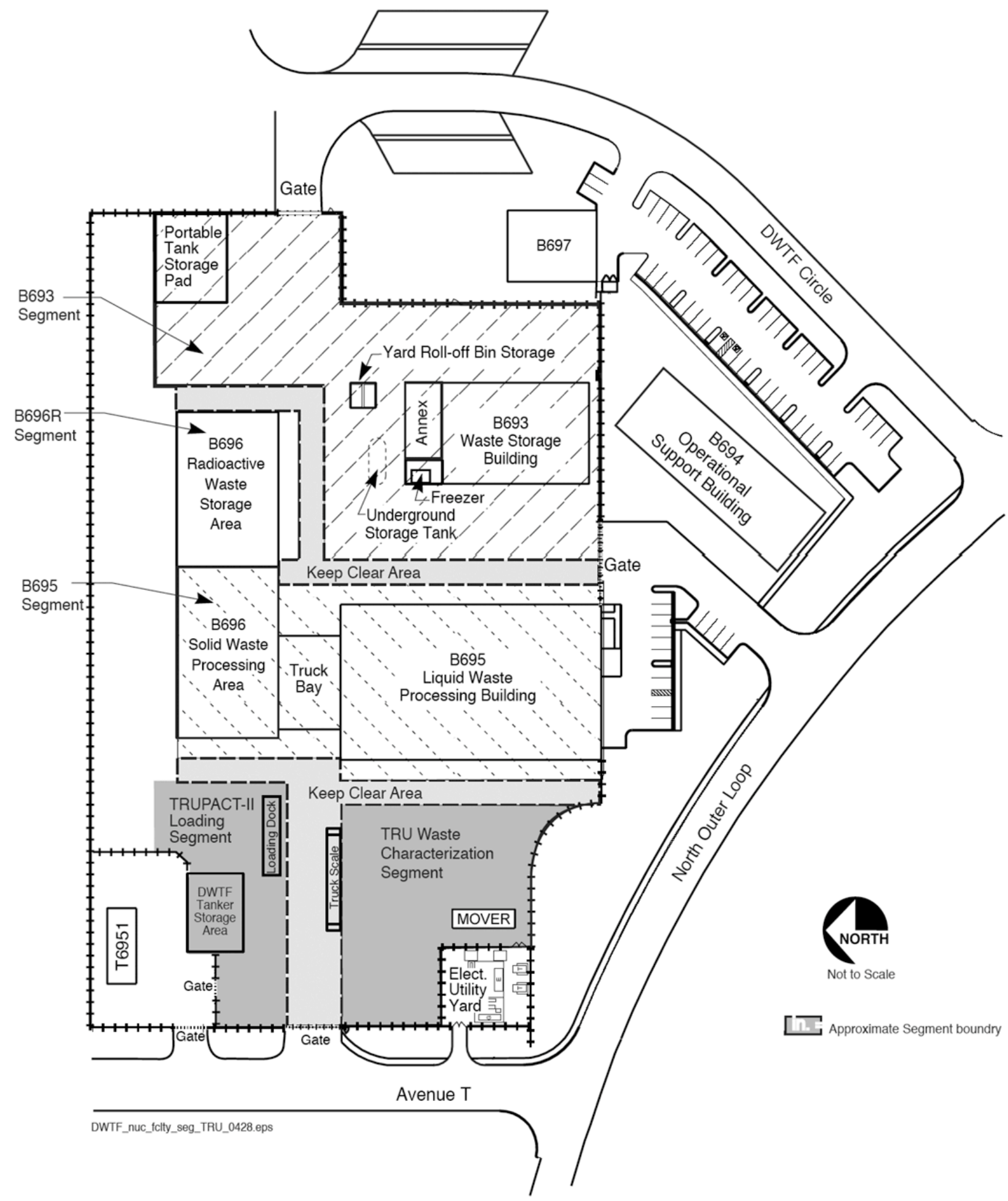

Figure 2. Layout of DWTF areas, showing the TRU waste characterization segment, TRUPACT-II loading segment, and location of the MOVER. 


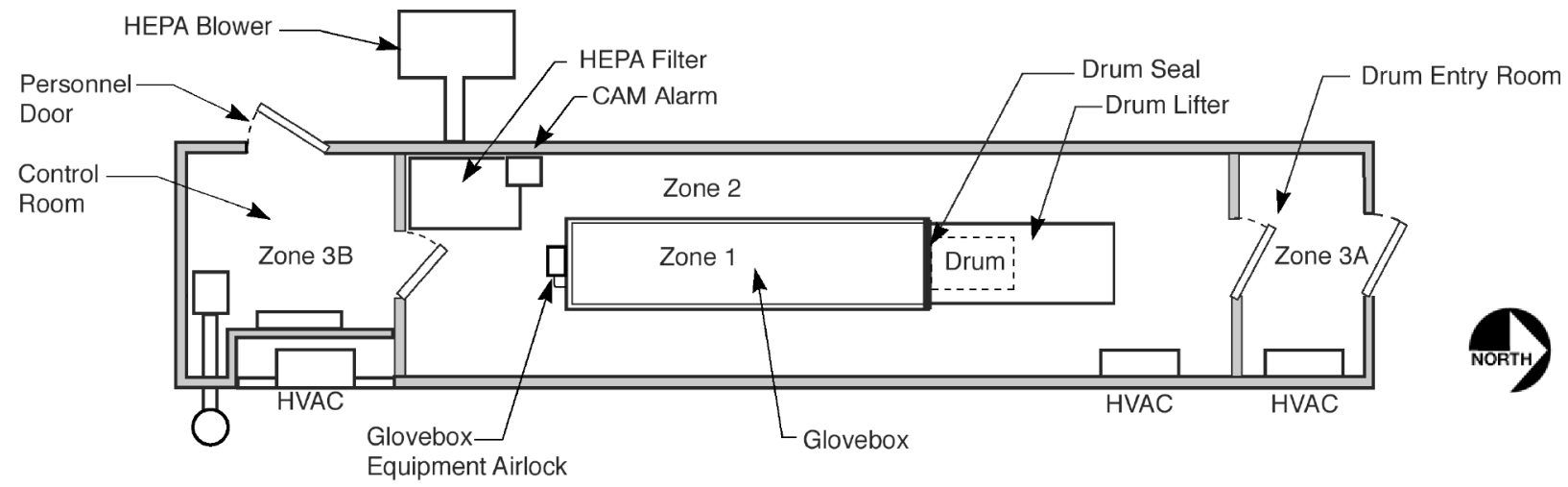

Figure 3. Interior layout of the MOVER, showing Zones 1, 2, 3A, and 3B; glovebox; drum lifter; continuous air monitor (CAM); heating, ventilating, and air conditioning (HVAC) unit; high-efficiency particulate air (HEPA) filter and blower; and other relevant features. 


\section{Event Description}

\section{Chronology}

Figure 4 shows the MOVER event timeline in detail. Refer to this figure for an overview of the sequence of events. At approximately $1055 \mathrm{hrs}$ on August 19, 2004, three qualified MOVER operators and one H\&ST donned respirators and personal protective equipment (PPE) and began work in the MOVER, Zone 2. The operators started the bag-out of a 27.3-PE Ci drum in accordance with CCP Procedure CCP-TP-042 and LLNL IWS 11359. Work was monitored by the H\&ST, who is a certified Radiological Control Technician. During the bag-out process, the operators noticed that the metal retaining band that surrounded the bag over the discharge ("in") drum port on the glovebox was not closing as tightly as normal. They also checked the band on the receiving drum port and noted wear on it. The operators continued with bag-out of the 27.3PE Ci drum by moving it out of the drum port, with the bag still attached to the port. They proceeded to crimp, tape, and cut the bag to form "horsetails" of the newly separated bag segments. They also bagged out the drum located below the glovebox that received the checked contents from the 27.3-PE Ci discharge drum using the same procedural steps.

During the bag-in process of the 0.6-PE Ci (or "full") drum, and in accordance with CCP procedures, the operators pulled back the stub of the bag (from the 27.3-PE Ci drum) on the "in" drum port (see Figure 6, later in this report, for details on the MOVER bag configuration). This action exposed an area of the exterior surface so that the bag of the 0.6-PE Ci drum could be placed over the sub of the 27.3-PE Ci drum bag and secured to the drum port. Because the newly exposed surface was within the contamination envelope, it was known to be contaminated by the operators. After pulling back the stub, the operators checked the exposed exterior area by wiping it with an oily cloth (Maslin) and then having the H\&ST survey the cloth. The H\&ST used a Blue Alpha survey meter and measured $6,000 \mathrm{cpm}$, approximately $12,000 \mathrm{dpm} / 100 \mathrm{~cm}^{2}$, on the Maslin swipe. The operators then decontaminated the area by first wiping it fully with wet cheese cloth and then dry cheese cloth. The area was swiped again with a Maslin cloth by the operators. The H\&ST did not detect any contamination and declared the area to be clean.

After successful decontamination, the operators began the bag-in of the 0.6-PE Ci drum in accordance with the CCP procedure and the LLNL IWS. As part of the bag-in, the operators replaced the metal retaining band surrounding the "in" discharge drum port. Because only one

spare retaining band was located inside the MOVER, the operators were not able to change the band on the receiving drum port. 
Figure 4. Event timeline.

NOTE: All indicated times are approximations.
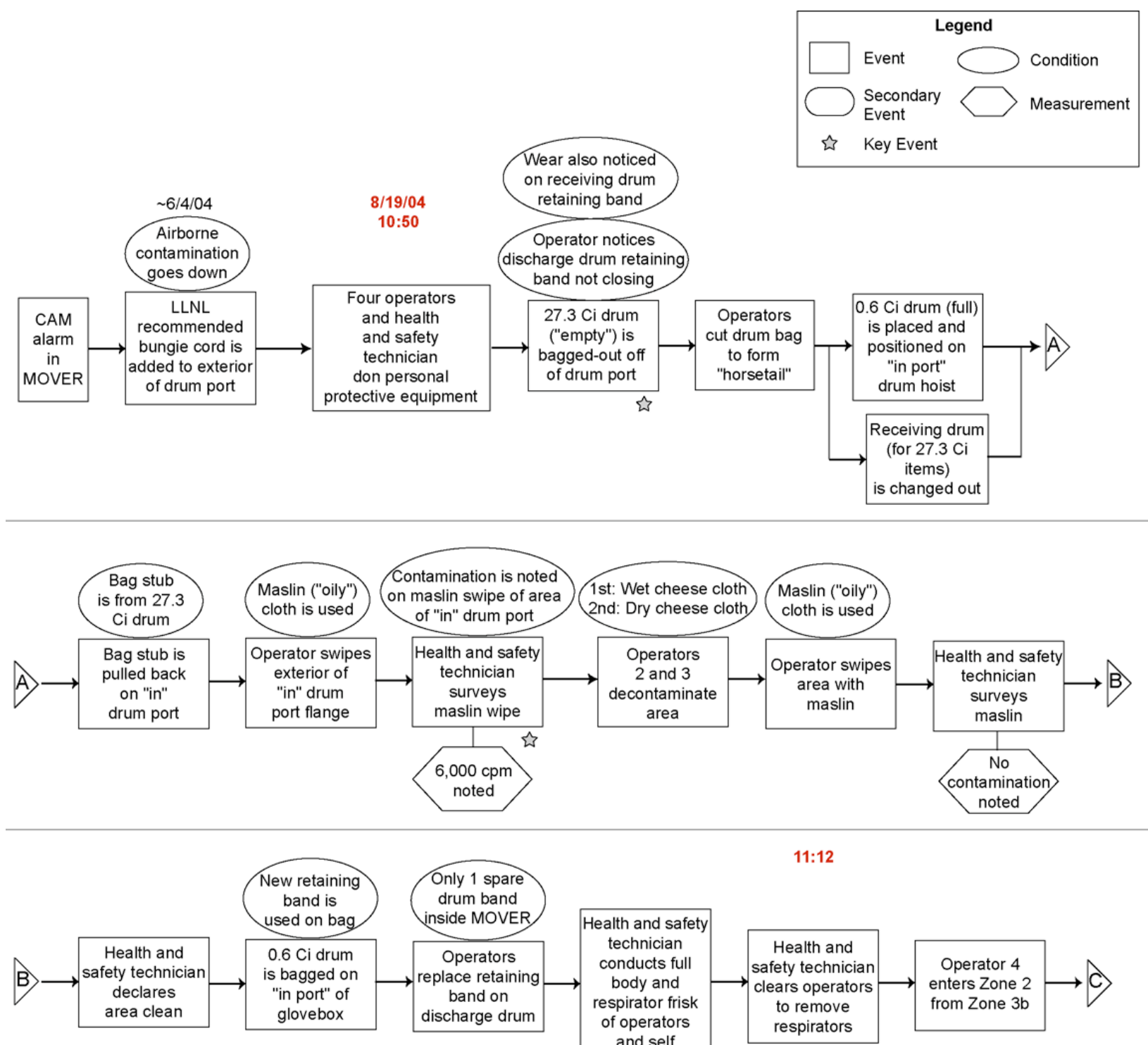

11:12
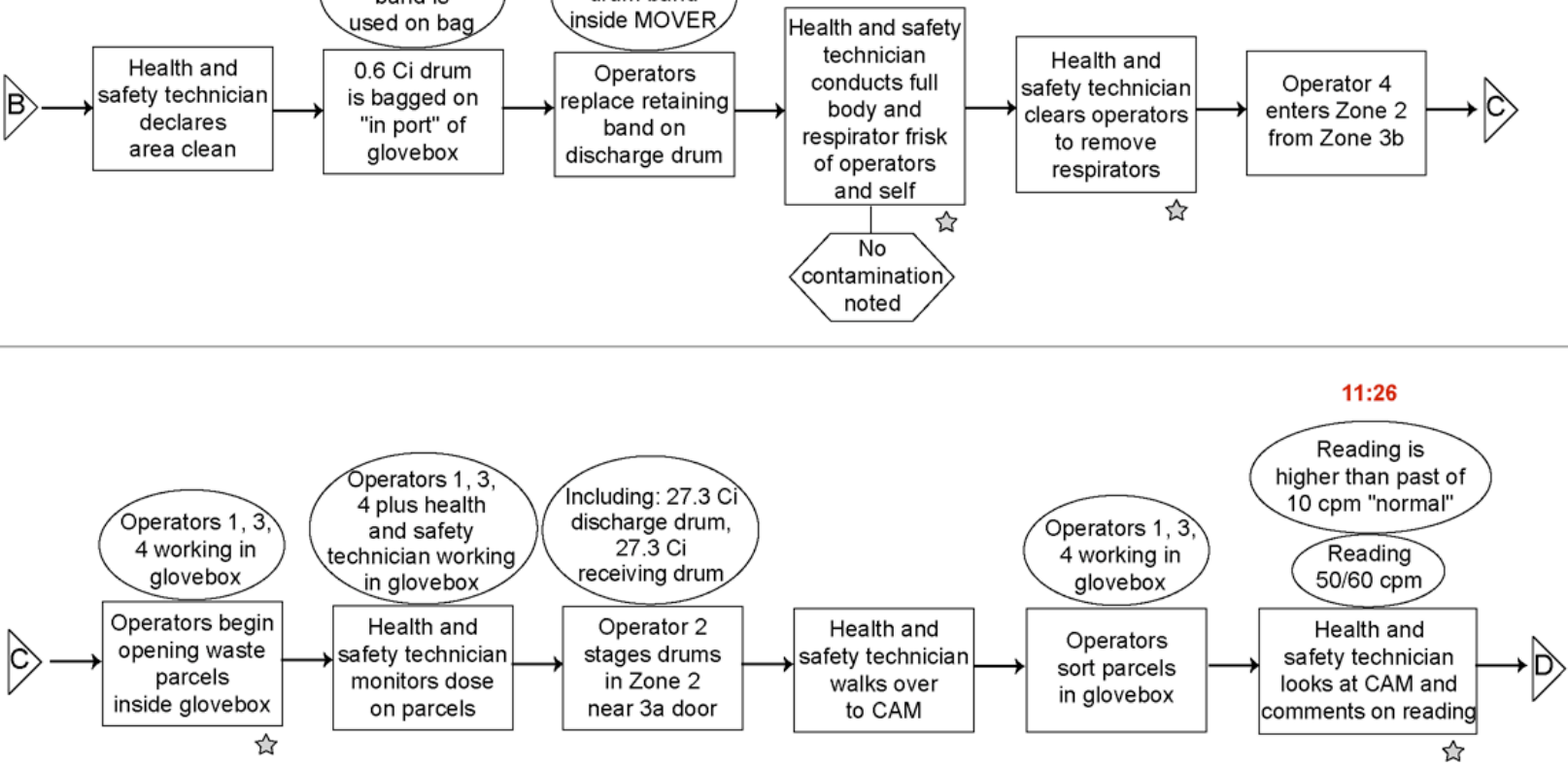


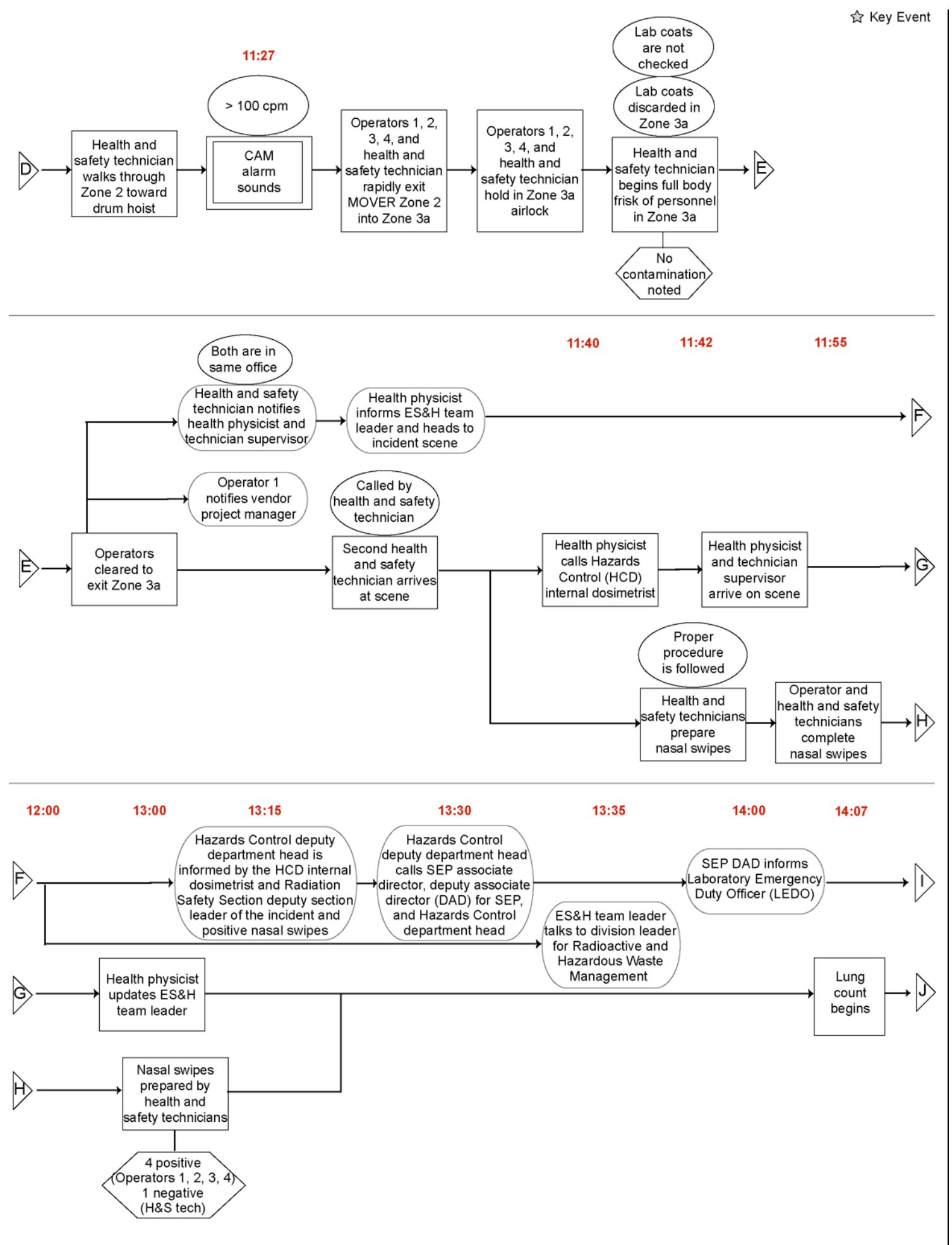

Figure 4. (Continued). 


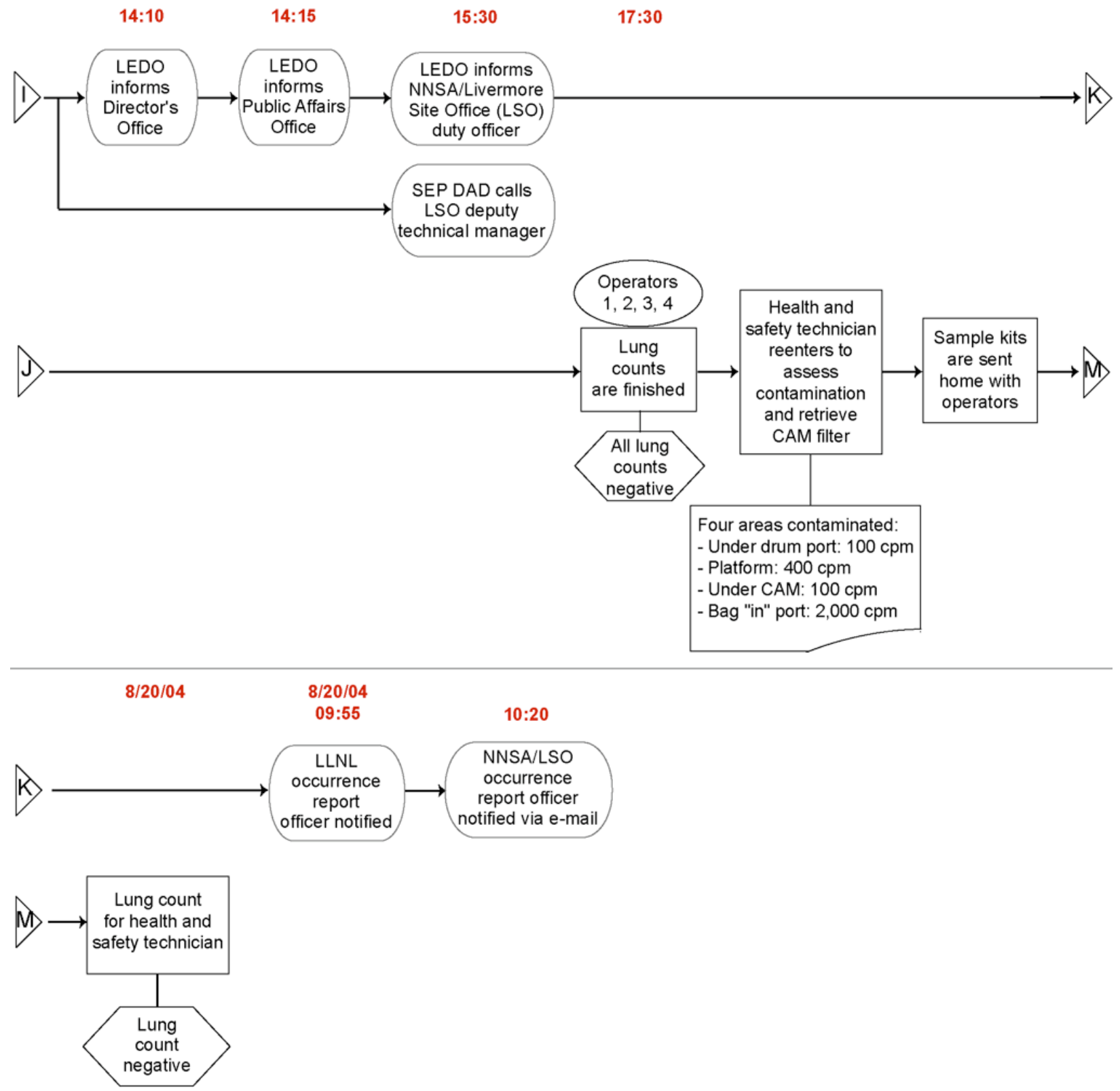

Figure 4. (Continued). 
Upon completing bag-out of the 27.3-PE Ci drum and the bag-in of the 0.6-PE Ci drum, the H\&ST conducted a full body and respirator frisk with a Blue Alpha survey meter of all personnel inside the MOVER. Once frisking was completed on all personnel, including the H\&ST, the H\&ST determined that no contamination was present and cleared all personnel to remove their respirators.

Operator 4 was then given permission to enter the MOVER, Zone 2. This individual was brought in to work under technical direction of the qualified CCP operators and to assist in drum remediation as part of the training. The CCP operators proceeded to place their hands into the glovebox glove ports and to open waste parcels from the 0.6-PE Ci drum in the glovebox.

As the operators sorted through parcels, searching for and retrieving prohibited items in the waste from the 0.6-PE Ci drum, the H\&ST, working in glove E-2, monitored the dose rates on the parcels. While this was occurring, Operator 2 was staging drums inside the MOVER. After approximately 10 minutes of work in the glovebox, the H\&ST walked along the east side of the MOVER to look at the Continuous Air Monitor (CAM). Upon reaching the CAM, the H\&ST commented to the operators that the readout on the CAM had risen higher than during past operations (typically $10 \mathrm{cpm}$ ) to between 50 and $60 \mathrm{cpm}$. The H\&ST then walked back along the west side of the MOVER towards the hoist end of the glovebox. Approximately one minute after the H\&ST observed and commented on the elevated CAM reading, the CAM alarm sounded. The CAM was set to alarm at $100 \mathrm{cpm}$ or greater.

On hearing the CAM alarm, all personnel inside the MOVER ceased working and immediately began exiting Zone 2 of the MOVER into Zone 3A (drum and personnel transfer airlock). Evacuation was done in accordance with CCP and LLNL procedures, which required that personnel hold in the airlock until surveyed out. Once all personnel were inside Zone 3A, they removed their lab coats, and the H\&ST conducted a full body frisk. No contamination was detected, and the H\&ST cleared personnel to exit the airlock out of the MOVER.

Operator 1 notified Vendor Manager 1 and the Facility Point of Contact (FPOC) of the event. The H\&ST called the ES\&H Team H\&ST Supervisor's office, who happened to be meeting with the Health Physicist (HP) assigned to RHWM. The H\&ST Supervisor immediately dispatched a second H\&ST to the facility. Upon arrival of the second H\&ST at the incident scene, the two Health and Safety Technicians began preparing nasal swabs for the operators and one H\&ST who had been present at the event. The HP informed ES\&H Team Leader 1 of the event and also called and briefed the Hazards Control Department (HCD) Internal Dosimetrist before heading to the incident scene. The H\&ST Supervisor arrived at the incident scene, took control of the response, and was soon joined by the HP. Nasal swabs were completed just before $1200 \mathrm{hrs}$ and sent for processing by the HCD.

The HCD Deputy Department Head was informed of the incident at approximately 1315 hrs by the HCD Internal Dosimetrist and RSS Deputy Section Leader. Being told of the four positive nasal swabs, the Deputy Department Head passed this information, approximately $1330 \mathrm{hrs,} \mathrm{to}$ the HCD Department Head, Associated Director, and Deputy Associate Director (DAD) of the Safety and Environmental Protection (SEP) Directorate who were together in a meeting. The AD 
requested assurance the program management was informed. The Deputy Department Head requested the ES\&H Team Leader 1 to assure the RHWM Division Leader was fully aware of the incident. The ES\&H Team 1 stated that the RHWM Division Leader had been informed.

Nasal swab results were reported to the Health Physicist (HP) at approximately $1300 \mathrm{hrs}$. The outcome was four positive and one statistically negative (the H\&ST). The positive nasal swabs were associated with both nostrils and ranged from four to 202 DPM alpha. The HP then updated ES\&H Team Leader 1, who informed the HCD Deputy Department Head, who, in turn, called the DAD for SEP. The DAD was in a meeting with both the AD for SEP and HCD Department Head. At approximately $1330 \mathrm{hrs}$, ES\&H Team Leader 1 talked to the Division Leader for RHWM at a meeting that had scheduled for another purpose.

At 1400 hrs, the DAD for SEP informed the on-duty Laboratory Emergency Duty Officer (LEDO) of the event and positive nasal swipes. This was the first call that the LEDO received concerning the MOVER event. The LEDO immediately called the Director's Office and left a message including the information that was available at the time. The LEDO next called LLNL's Public Affairs Office at $1415 \mathrm{hrs}$. At approximately $1530 \mathrm{hrs}$, the LEDO received a call from the NNSA/LSO Duty officer, who the LEDO briefed on the event.

Based on the positive nasal swipes, lung counts were started for all personnel who were inside the MOVER at the time of the CAM alarm. By $1730 \mathrm{hrs,} \mathrm{the} \mathrm{lung} \mathrm{counts} \mathrm{for} \mathrm{the} \mathrm{four} \mathrm{operators}$ were completed, and all were negative. Urine and fecal sample collection kits were sent home with the operators.

After securing authorization from the HCD to re-enter the MOVER, the H\&ST wore a respirator, entered the MOVER to assessed contamination, and retrieved the CAM filter paper. The H\&ST identified four areas of contamination, as follows:

- $\quad$ Area directly underneath the drum port (100 cpm).

- The platform (400 cpm).

- $\quad$ Area under the CAM (100 cpm).

- Bag-in port (2000 cpm).

The H\&ST exited the MOVER, which was then secured pending investigation and recovery plans. The following day, the H\&ST received a lung count, which was negative. Urine and fecal samples were also collected for the H\&ST.

\section{Health Physics Considerations}

The amount and types of radioactive materials handled in the MOVER present a hazard that requires controls be implemented to safely perform required tasks without negative consequences. Controls include design and engineering controls, such as the glovebox and ventilation systems, and administrative controls, such as inspections, procedures, and training. 
Design and engineering controls of the MOVER, along with operational safety procedures, were presented to LLNL as part of a packaged operation.

When the safety margin is compromised during certain phases of operations (such as bag-in and bag-out), PPE - including gloves, coveralls, lab coats, and respirators - are used to mitigate potential personnel contamination or uptake of airborne radioactivity by personnel in the MOVER. Monitoring of the radiological environment for external dose rates, airborne radioactivity, and loose radioactive contamination is performed to verify the adequacy of the radiation protection program and to notify personnel of problems with the program. When safety margin conditions were restored while work was being performed in the MOVER, a full-body and respirator frisk of operators for contamination was conducted by the H\&ST. Airborne radioactivity was being measured by the CAM, but short of an alarm condition, no criteria were established in the procedures or IWS for determining when to remove respirators. Radiological hold points for airborne radioactivity and the basis for removing respirators were both lacking. Thus, removing respirators during operations is a factor in operator uptakes prior to the August 19, 2004, event.

LLNL's ES\&H Team provided radiological controls and monitoring. Monitoring requirements were specified in the Health Physics Discipline Action Plan (HP DAP). Previous experience at Argonne National Laboratory (ANL) indicated that CCP personnel and their equipment were capable of performing similar work without incident. For example, more than 400 drums were process at ANL without incident, with the exception of a minor contamination event involving a pass-through port no longer used by MOVER personnel. Thus, past performance indicated that there was little potential for airborne radioactivity or major contamination events.

Radiological work began in the MOVER on April 1, 2004, and involved the following activities:

- Inserting a parent drum in the bag-in port of the MOVER glovebox.

- Removing the daughter drum.

- Remediating and/or inspecting the contents in the glovebox with gloves.

- Bag-out of the receptacle drum.

- Decontaminating drum ports.

- Radiological surveys of contents of the drums.

- Drum handling inside the MOVER.

Prior to radiological work, background air samples were collected by a CAM, beginning on February 24, 2004. HP 1 also decided to place the MOVER workers on monthly bioassay because he thought that the MOVER workers were only going to be at LLNL for five months. If bioassays were taken quarterly, as is the normal practice, the HP would get only one sample. Beginning March 30, 2004, a passive air sampler was added to the right side of the MOVER. The following week, another passive air sampler was added on the left side. Air samples taken after radiological work began to indicate that a chronic airborne radioactivity condition was present in the MOVER from April 1, 2004, through August 19, 2004 (Figure 5). Many of the 
samples were of low activity-less than $10 \%$ of Class W Pu239 Derived Air Concentration (DAC). Some were greater than $30 \%$ of a DAC, which would have required posting the MOVER as an Airborne Radioactivity Area, in accordance with 10 CFR 835, Occupational Radiation Protection (835), and the LLNL ES\&H Manual.

The purposes of the Internal Dose Monitoring Program at LLNL are to:

1. Detect and confirm any significant intakes of radioactive materials.

2. Meet regulatory requirements (10 CFR 835) for monitoring of workers and management of internal doses.

3. Assist Hazards Control and LLNL Program and Facility Management in assuring that any internal doses are kept to levels that are ALARA.

4. Provide assurance that engineered and administrative workplace controls are effectively protecting workers.

5. Document the presence or absence of internal contamination in LLNL workers.

6. Assess internal doses from any intakes that occur.

Components of this Internal Dose Monitoring Program include bioassay (both in-vivo and invitro measurements), air sampling and monitoring, surface contamination monitoring, and personnel contamination monitoring. In workplaces where transuranic elements are handled, workplace monitoring (air, surface, and personnel contamination) will typically provide the most rapid and sensitive indication of less-than-adequate workplace controls. 


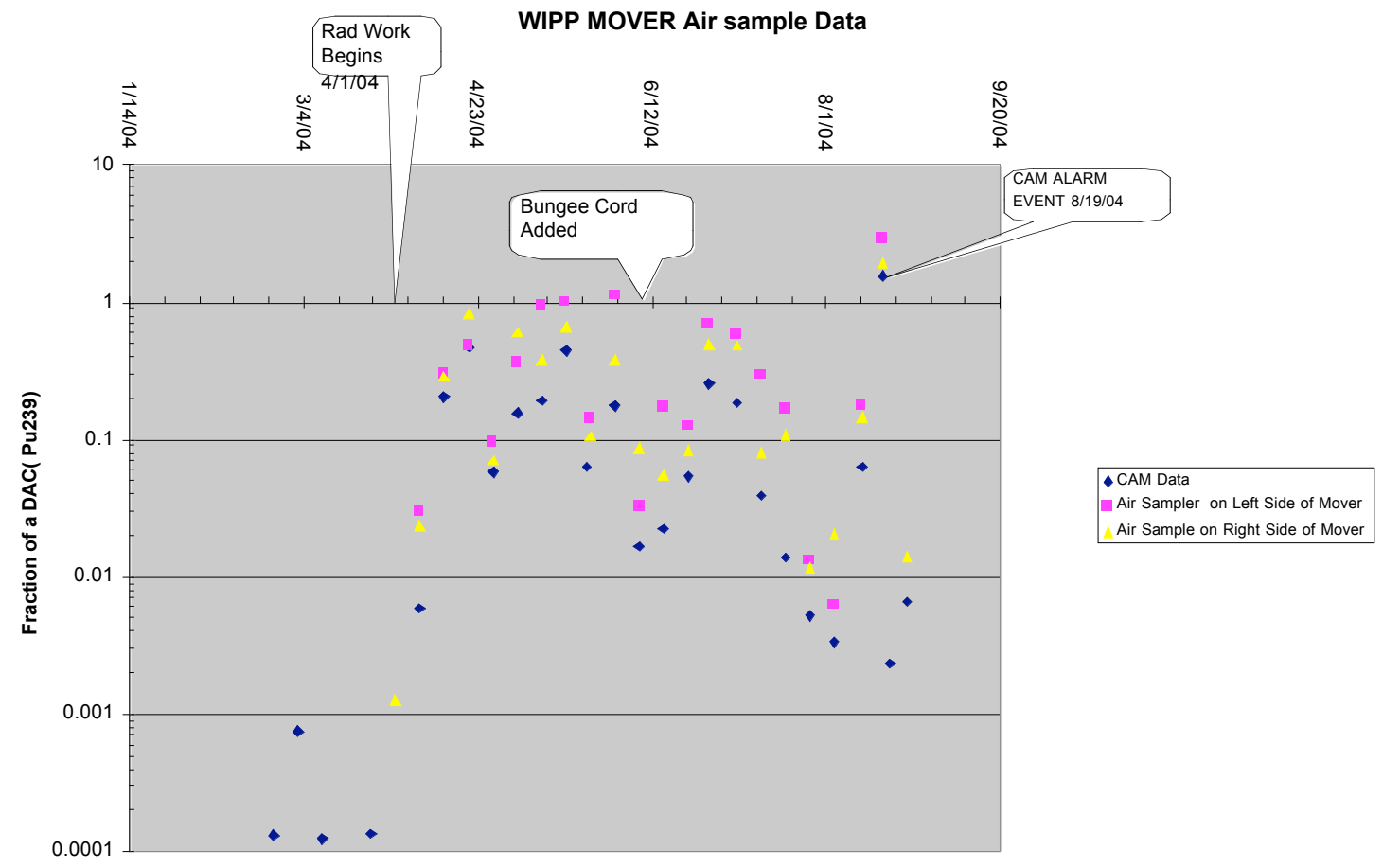

WIPP MOVER Air sample Data

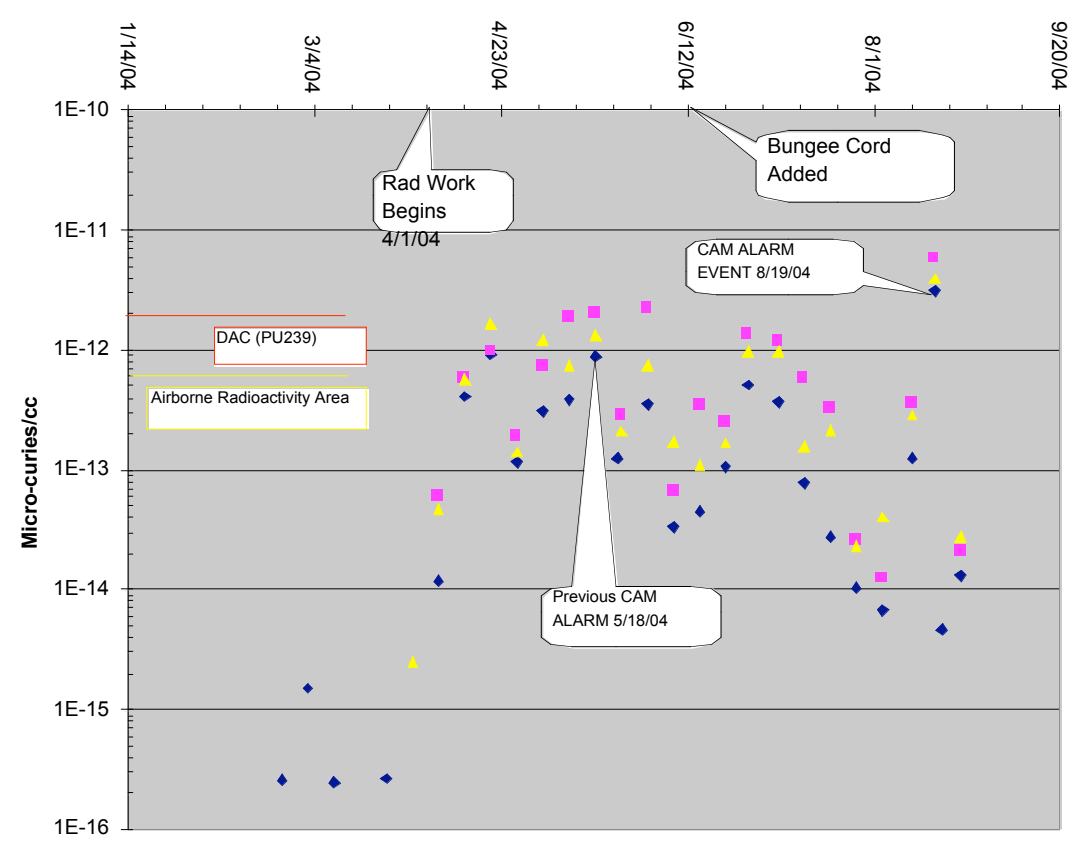

Figure 5. Air sample data show a chronic airborne radioactivity condition present in the MOVER from April 1, 2004, through August 19, 2004. 
Most of the positive airborne radioactivity samples were less than the activity level that would have caused the CAM to alarm, and many were below the notification level employed by the Radiation Measurements Laboratory (RML) of $10^{-13} \mu \mathrm{Ci} / \mathrm{ml}$. As a precaution, the HP placed MOVER workers on a monthly bioassay program versus the standard semi-annual sampling program. Radioactive contamination control swipes indicated that very little contamination was spread during the entire period of MOVER operation.

On August 19, 2004, the CAM alarmed, and nasal swabs were taken. Nasal swabs were positive, as were all air samples in the MOVER. Air samples of the event indicated that airborne radioactivity in the MOVER exceeded 1.5, 2.01, and 2.95 DAC for the CAM, right-side passive air sampler, and left-side passive air sampler, respectively. The samples are averaged over a 3day sampling period, whereas samples are normally averaged over 7 days. The actual activity concentration in the MOVER during the event was probably much higher and occurred over a period of about 60 minutes.

After the August 19, 2004, CAM alarm event, monthly bioassay samples were pushed up in the queue. Results indicate that airborne radioactivity occurred when respirators were not being worn during the entire period that the MOVER was operating. This finding agrees with the occurrence of radioactive contamination around the bag-port after decontamination of the port during bag-in operations. Indications are that leakage at the bag/bag port interface was occurring during operations inside the glovebox and that may have been the source of contamination from the beginning of operations.

\section{Potential Sources of Airborne Radioactivity from Glovebox Operations}

The following potential causes were considered when attempting to identify the source of airborne radioactivity:

- In keeping with Quality Assurance requirements for headspace gas sampling for waste characterization, a small slit was made in the receiving bag in the bag-out port prior to closing the lid. Such action has the potential to release radioactivity from the contents and make it airborne. HP 1 recommended to LLNL and CCP project managers that this practice be stopped shortly after the beginning of operations in April.

- Because of the method of bag-on and bag-off employed by MOVER operators, several inches of contaminated bag port were exposed and subsequently decontaminated by wiping the contamination. The mechanical action of decontamination can cause material to become airborne. During such operations, workers are protected against airborne radioactivity with full-face respirators. Approximately 60 minutes elapsed from the previous decontamination efforts to the time the CAM alarmed on August 19, 2004. Less than 1 minute elapsed from the time the H\&ST noticed a reading of approximately $50 \mathrm{cpm}$ to the CAM alarm at $100 \mathrm{cpm}$. The time delay between decontamination of the port, and the rate of increase leading to the CAM alarm, indicate that the act of decontamination was not the source of material that caused the CAM alarm.

- Leaks in gloves were considered. Radiological surveys indicated no breaches of the integrity of gloves on the MOVER glovebox on August 19. Leaks in gloves were noted 
on May 10, June 7, June 24, June 29, and July 6. These leaks could have contributed to some airborne contamination before the August 19 event; however, they do not explain all of the pre-event readings and do not explain the airborne activity on August 19.

- Leaking waste drums were considered. Radiological surveys of drums inside the MOVER indicate no leakage of drums or their contents.

- Large, unnoticed spills during operations were considered. Radiological surveys taken after the CAM alarmed indicate only small levels of spotty contamination present. The amount of material was not large enough to cause airborne contamination in the amounts observed from air samples.

- Leaks around exhaust ducting or the glovebox were considered. Radiological surveys indicate no leakage in these areas.

- Leakage around glovebox bag seals was considered. Visible channels are located under retaining rings and at the edge of the bag-sealing surface. MOVER personnel do not tape the end of the bag to the port, so these channels provide a pathway out of the glovebox for material contaminating the bag port. Changes in glovebox pressure from pumping action when personnel are in the glovebox may cause the glovebox to become temporally positive with respect to the MOVER. Indications (e.g., low-vacuum alarm) suggest that box pressures changed during glovebox operations. This appears to be the most likely source of airborne radioactivity because contamination was found around the bag-in port after it was decontaminated and a new, clean bag was placed on the port.

\section{Early Warning and Actions Taken to Address Airborne Radioactivity Concerns}

Low levels of airborne radioactivity prompted HP 1 to investigate a potential cause and possible solutions. As a result, the HP and project manager required that the slitting of bags be stopped and the QA requirement be met by other means.

On May 19, 2004, the CAM alarmed in the MOVER (no nasal swabs were taken). No personnel were in the MOVER and the CAM was in the alarming mode when personnel arrived for work the next day. An alarm notification light on the exterior of the MOVER notifies personnel not to enter the MOVER if the CAM is in the alarm mode. The alarm was attributed to radon daughter buildup on the sample filter. Subsequent analysis of sample filters indicated that the filters had positive levels of radioactivity for transuranics. Toward the end of May 2004, the HP noticed that a persistent level of airborne radioactivity was present on the sampling filters, even after ceasing the slitting of bags. (Note: There is disagreement among those interviewed on the date the practice of slitting of bags was stopped. Some recall this date to be in April; others place the date as late as June.)

Swipes were taken to determine the effectiveness of the radiation protection program. Contamination outside of controlled areas would be an indicator of a poor program. Weekly swipes were taken throughout the waste-handling process in the MOVER. The following areas were swiped weekly in accordance with the HP DAP: 
- Entrance floor.

- Floor in hot zone.

- Drum hoist.

- Table in hot zone.

- Bag-in drum port.

- Floor, left platform.

- Floor, right platform.

- Glovebox ports, left side.

- Glovebox ports, right side.

- Floor under glovebox.

- Floor under 55-gal port.

- Floor on south door.

- Floor in Zone 3B.

- HENC rollers.

- Plastic underneath bag-in port.

- Local exhaust vent in MOVER.

- Ladder in MOVER.

- Top of glovebox.

- Background.

Of the 354 swipe samples taken, only the 8 samples shown in Table 1 indicated any contamination above contamination control limits of $20 \mathrm{dpm} / 100 \mathrm{~cm}^{2}$.

Table 1. Results of swipe samples showing contamination greater than control limits.

\begin{tabular}{|c|c|l|}
\hline Sample date & $\begin{array}{c}\text { Result } \\
\left(\mathbf{d p m} / \mathbf{1 0 0} \mathbf{~ c m}^{\mathbf{2}}\right)\end{array}$ & \multicolumn{1}{|c|}{ Sample comments } \\
\hline 3 May 2004 & 48.7 & Bag-in drum port \\
\hline 4 Jun 2004 & 23.1 & Bag-in drum port \\
\hline 4 Jun 2004 & 20.8 & Glovebox ports, left side \\
\hline 21 Jun-04 & 20.4 & Floor on south door \\
\hline 25 Jun 2004 & 21 & Glovebox ports, left side \\
\hline 7 Jul 2004 & 35.3 & Glovebox ports, left side \\
\hline 19 Jul 2004 & 23.1 & Top of glovebox \\
\hline 30 Jul 2004 & 27.1 & Top of glovebox \\
\hline
\end{tabular}


The minimal level of detectable contamination indicates a fairly robust radiation protection program. When the amount and types of radioactive materials processed in the MOVER are taken in consideration, the results also suggest proper radiological controls by workers.

The DAP did not require that swipes be taken of the drum port because that port was expected to be contaminated. Swipes not associated with DAPs are not normally turned in for analysis by the RML. Thus, there was no sample of the amounts of radioactive contamination present on the bag ports. Nevertheless, anecdotal information indicates that, at times, 20,000 cpm (roughly equal to $40,000 \mathrm{dpm}$ ) was present on wipes taken at the exposed bag-sealing surface, until the bungee cord was added. According to MOVER personnel, contamination was reduced on the drum port dramatically after addition of the bungee. The most notable amount on the port occurred in the bag-in operation of the drum prior to the CAM alarm.

The other obvious source of contamination outside of the glovebox is the radioactive contamination that is present and exposed to the MOVER environment during bag-on bag-off operations. The levels of airborne radioactive contamination observed prompted the HP to consult with the Radiation Safety Section (RSS) for support to help reduce the amount of contamination occurring at the bag ports on the MOVER glovebox. An HP subject-matter expert (SME) observed a bag-off operation and made several recommendations, including:

- Using an additional elastic (or plastic tape) on the bag seal, as close as possible to the bottom of the sleeve to help minimize contamination on the sleeve surface that is exposed during change-out.

- Placing a cover on at least one of the passive air samplers during respirator operations.

- Reviewing procedures for actions to be taken for a CAM alarm when personnel are in respirators.

- Modifying procedures, as needed.

The suggestion to add an elastic band around the glove bag, between the upper and lower rib of the bag port, was accepted in view of the fact that the Vendor Manager did not believe it would require a procedure change. Changes to procedures required several weeks of review by Washington TRU Solutions (WTS) management before implementation and would have a major impact on the schedule, if work was stopped for a procedure change. The addition of the bungee cord was also seen as an augmentation of the safety program. The change was discussed and approved by LLNL and CCP project managers. The IA Team viewed glovebox operating procedures and glovebox design to be directly linked and that changes to either should have a safety review by CCP. The MOVER operators added a bungee cord around the bag ports in keeping with recommendations. The immediate effect of adding the bungee was to lower the contamination occurring at the sealed end of the bag and to lower the airborne radioactivity in the next week's air sample. However, the airborne radioactivity results quickly returned to levels above $10 \%$ of a DAC. It is not possible to conclusively credit the installation of the bungee cord for minimizing airborne contamination because the Material at Risk (MAR) during this time was changing. 
No further actions or notifications from the HP were made after levels returned to the previous level. This was the case because the low level of airborne radioactivity was believed by the HP to be airborne radioactive contamination from activities (i.e., bag-on and bag-off operations) that were occurring during a time when workers were wearing respirators. 


\section{Current Evaluation of Dose Consequences}

Table 2 shows the current estimate of Committed Effective Dose Equivalent (CEDE) to workers in the MOVER.

Table 2. Preliminary estimate of possible range of doses for MOVER workers.

\begin{tabular}{|c|c|c|c|}
\hline & \multicolumn{3}{|c|}{ CEDE (rem) } \\
\hline Worker & Upper range & Lower range & Current estimate \\
\hline Operator 1 & $\sim 5$ & 0.5 & $\sim 2$ \\
\hline Operator 2 & $\sim 10$ & 0.5 & $<5$ \\
\hline Operator 3 & $\sim 10$ & 0.5 & $<5$ \\
\hline H\&ST 1 & $\sim 10$ & 0.5 & 2 \\
\hline Operator 4 & $\sim 5$ & 0.1 & 0.5 \\
\hline
\end{tabular}

Notes:

Dose ranges include doses from multiple intakes that may have occurred prior to the August 19, 2004, CAM alarm event, and any intakes that occurred on August 19, 2004. The range of uncertainty reflects the following factors, all of which are unknown as of this date:

- Number of intakes for each worker.

- Dates of intakes for each worker.

- Quantity of each intake.

- Mix of radionuclides for each intake.

- Solubility of materials for each intake.

- $\quad$ Particle size distribution of each intake.

There are two DOE dose limits: a 5-rem limit on CEDE and a 50-rem limit for the Committed Dose Equivalent (CDE) to any organ or tissue. In cases of uptakes of transuranic elements, it is likely that the limiting dose (the dose limit that is exceeded first) is the CDE to bone surfaces. 


\section{Drum Bag and Bag-Out Port Safety}

Indications of elevated airborne contamination of radioactive material suggest a loss of confinement. The loss associated with the MOVER event can be caused by a breach in glovebox confinement or the techniques used to perform operations, such as removing material from gloveboxes (e.g., bag-ins, bag-outs, and bag changes).

The IA Committee evaluated the bag ports used on the MOVER glovebox (Figure 6) and compared them to the installation and design of similar bag ports at the LLNL Plutonium Facility (Figure 7), which is located in Building 332. The two types of bag ports are similar in design. However, the MOVER bag port is considerably larger to accommodate a 55-gal drum, whereas Plutonium Facility ports have a diameter of typically $\sim 20$ in. The larger size would not, in itself, have an affect on maintaining confinement of radioactive material.

The material used to construct the MOVER drum bag is much less pliable than material used in the LLNL Plutonium Facility bags. Stiffness can have a detrimental effect in achieving a bag seal to bag port. The stiffness of material tends to pucker bag material close to the rubber retaining band. Puckering of material creates micro-channels that allow contamination to make its way under the rubber retaining band and into the working area. In addition, the material used on the MOVER's rubber retaining band appears to be too elastic when compared to an O-ring used at LLNL's Plutonium Facility. The latter provides a measurable stretch and compression force. The rubber retaining band used on the MOVER is connected with a metal clamp that will not bend to conform to the round bag port and provide a seal. This condition allows for an area under the band, with no direct seal to the bag port. The seal is critical when a bag is being changed, and the rubber retaining band provides the only contamination seal between the glovebox and workers. A second seal of the bag to the port is a retaining clamp (hose clamp). This seal also allows for leakage when tightened, because the bag tends to gather, forming micro-channels, and resulting in a leak path. The clamp-tightening mechanism (see Figure 8) also has a gap under it that provides a leak path. This condition allows for an area under the band with no direct seal to the bag port.

During the August 19, 2004, event, MOVER operators observed that the retaining band was not tightened adequately. CCP personnel attributed the problem to a worn clamp-tightening screw, and the clamp was subsequently replaced. The IA Committee believes that the clamp mechanism was never completely effective even in its normal state, and its degraded condition would have allowed more contamination to make its way through the retaining clamp to the area up to the rubber retaining ring. A third mechanism for providing a contamination seal (installed in June as suggested by LLNL ES\&H personnel) was a bungee cord installed around the bag on the outboard side of the hose clamp to attempt to seal the drum bag to the bag port. The bungee cord had several knots, and the end hooks were still attached. The presence of knots and hooks, and the absence of pressure adjacent to them, provided for channels that contamination could pass through. Although the bungee cord may have had some effect on reducing contamination on the glovebox bag port, it was not totally effective as a seal. 


\section{Mover Bag Configuration}

Working Configuration

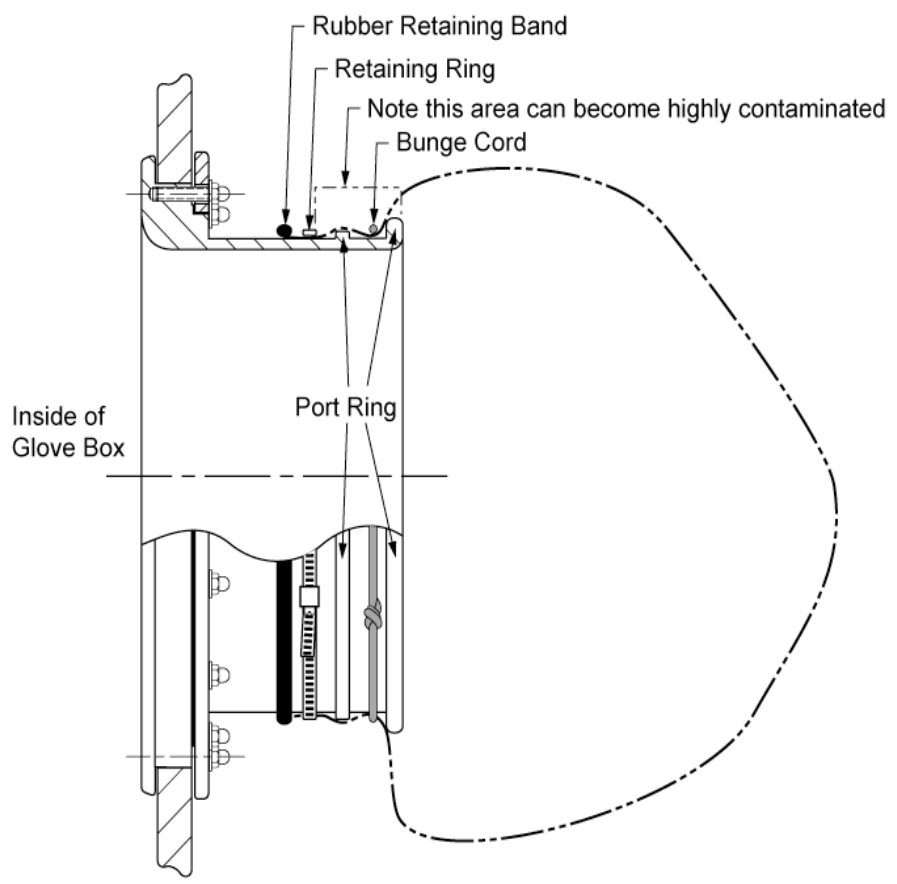

Bag Change Configuration

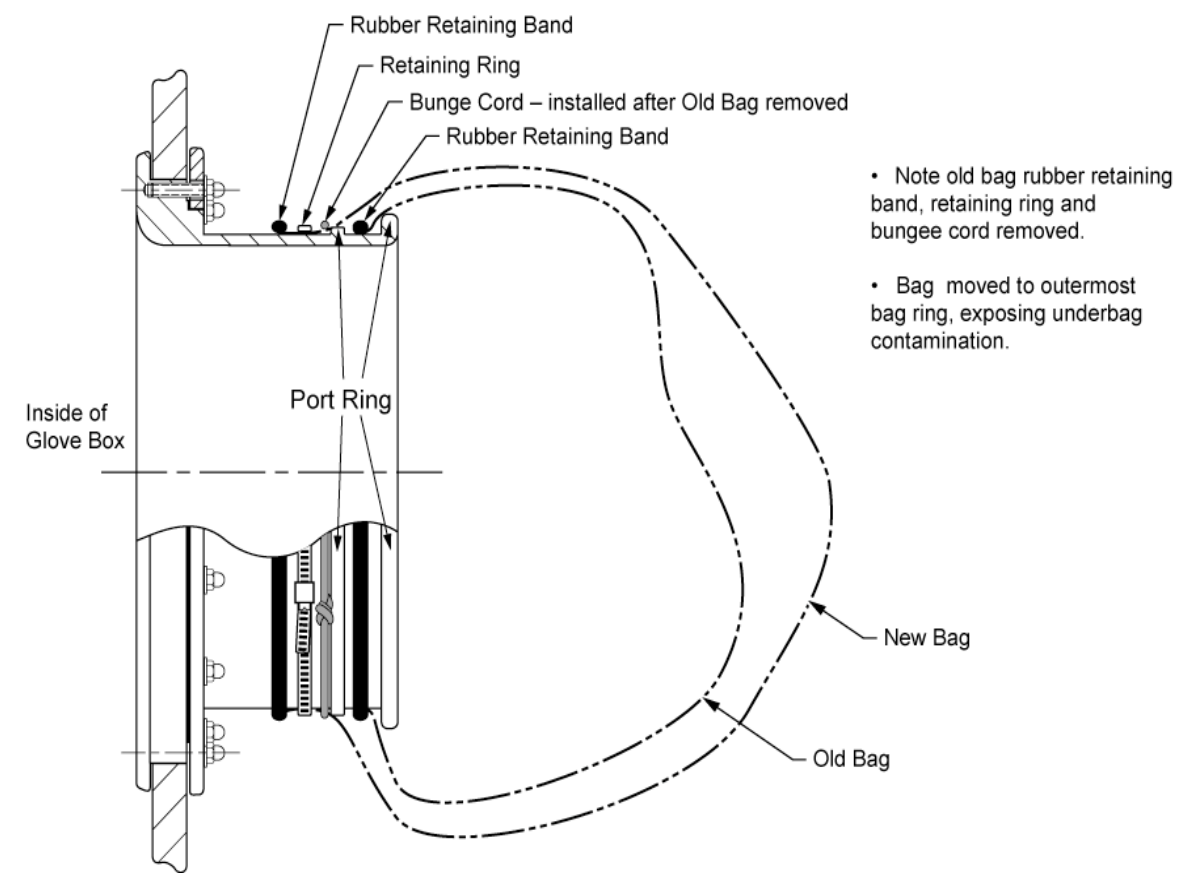

Figure 6. MOVER working configuration (top) and bag-change configuration (bottom). 


\section{LLNL Bag Configuration}

Working Configuration

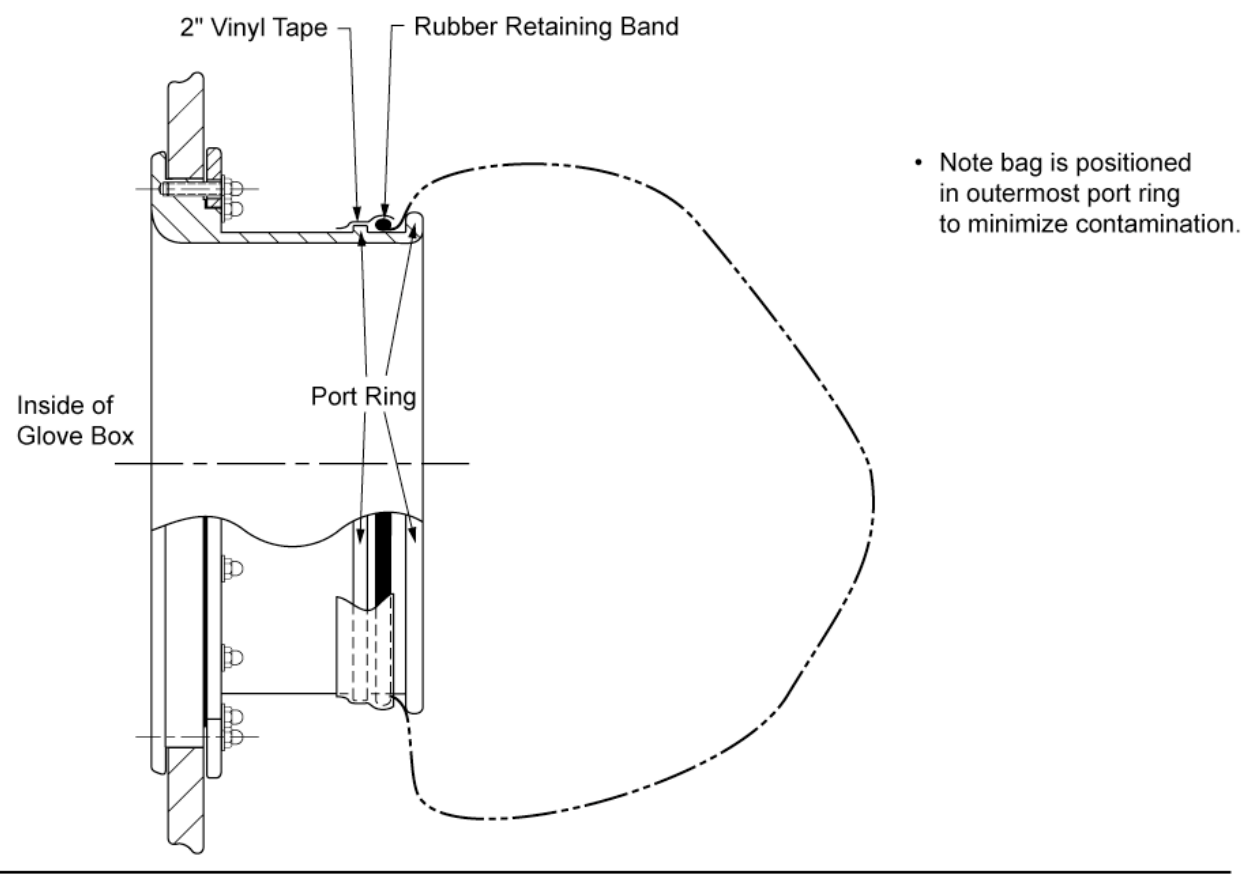

LLNL Bag Change Configuration

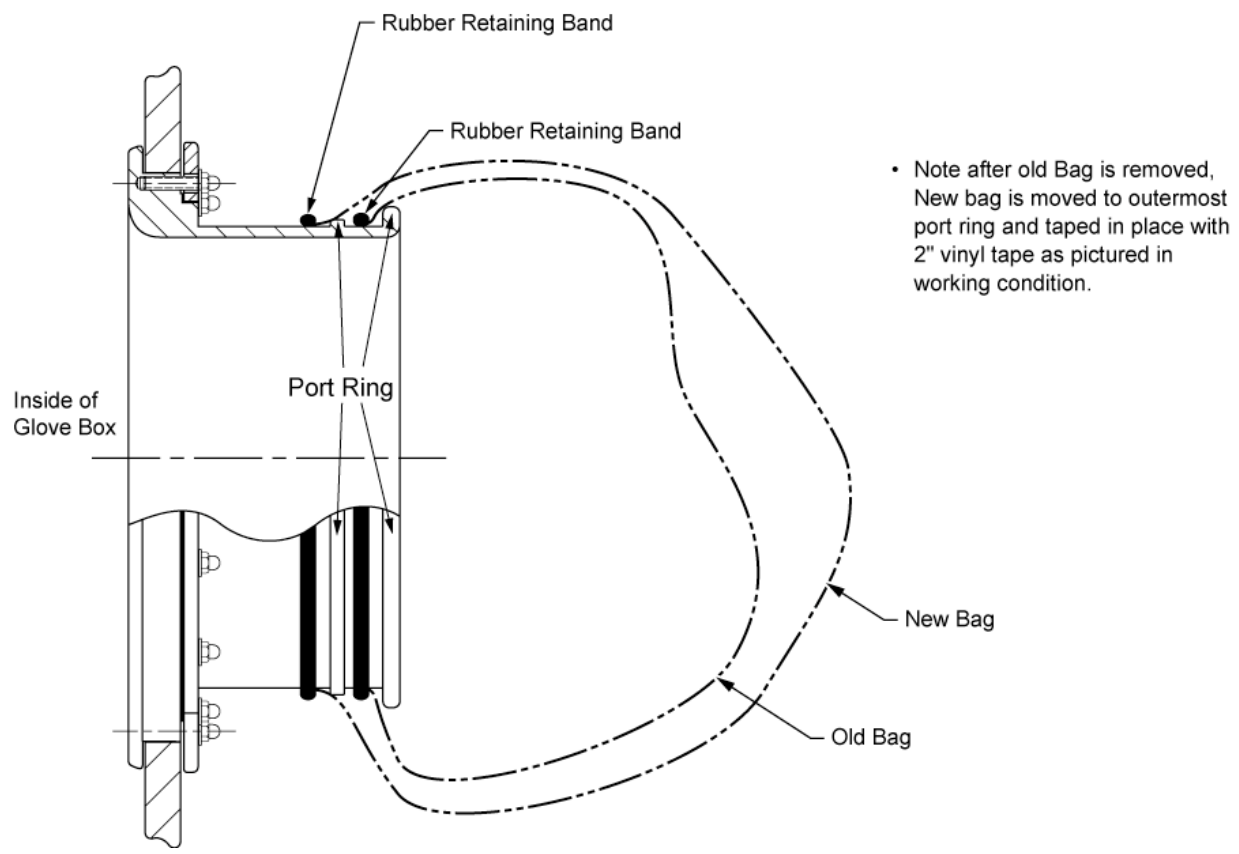

Figure 7. LLNL Plutonium Facility working configuration (top) and bag-change configuration (bottom). 


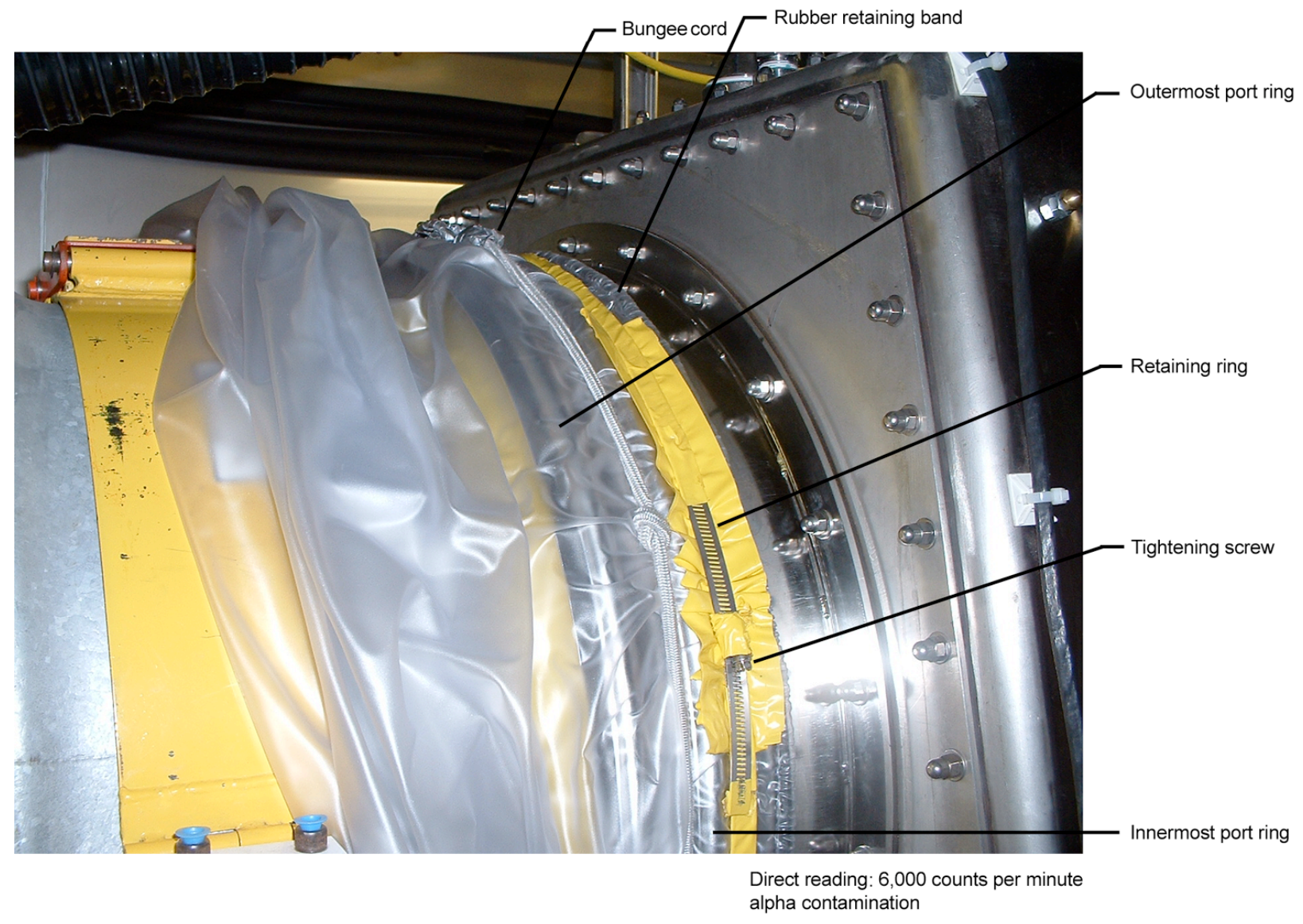

Figure 8. Photo of MOVER configuration, August 19, 2004, showing bungee cord, rubber retaining band, retaining ring, and tightening screw. 
Thus, the three sealing methods discussed above each provided a tortuous pathway for material to enter the air in the MOVER. As a result, a small amount of material could easily escape through the three compression seals because each had a leak path to the next seal, and eventually through the bag port interface.

Techniques used in the MOVER to secure the drum bag to bag port, as well as bag-changing techniques, are considerably different from the techniques used at the LLNL Plutonium Facility. The techniques used by CCP provided an opportunity for contamination on the bag port when changing a drum bag. Figures 6 and 7 compare the techniques used at the MOVER to those used at the LLNL Plutonium Facility.

When bags at the MOVER are left on the innermost port ring (closest to the glovebox), contamination can migrate along the port ring. When a bag needs to be changed, personnel remove the retaining (hose) clamp and rely completely on the rubber retaining band and move it to the outermost port ring. This operation physically scrapes areas that were previously exposed to the glovebox environment and leaves them exposed. Contamination in excess of tens of thousands of counts was observed on the bag port. The area was then decontaminated before the bag-change process continued. The Incident Analysis Team believes that operating processes resulting in conditions that required routine decontamination are less than adequate. Moving the drum bag to the first port ring could eliminate this contamination area along with the need to continuously clean the area of contamination. The combination of bag design and baginstallation techniques resulted in leak paths for contamination to exit the MOVER glovebox and become airborne.

Whereas the CCP design used two contamination rings to provide a seal, neither was effective. HP 1 and the HP SME identified the potential for leakage at the bag/bag-port interface. Their recommendation for an additional bag seal (bungee cord) was also ineffective in correcting this leak path. A positive seal of bag to the bag port is needed. A demonstrated and effective way to accomplish such a critical seal is to use 2-in.-wide vinyl tape overlapping the bag to the port.

Several CCP workers stated that ventilation alarms (low vacuum) in the glovebox were commonplace, as was the acceptance of contamination. When CCP employees were questioned on the significance of these alarms and contamination, they responded that - as long as the alarm cleared and the contamination could be cleaned up - this was not a problem. A low-vacuum alarm in the glovebox condition does not indicate the level of vacuum beyond the set point or even if the pressure in the glovebox had gone positive. Operating with any alarms, whether they reset or stay locked in, have significance, just as recurring contamination does.

It appears that maintaining confinement of contamination was lacking in the interface between the drum bag and the glovebox bag on port, as well as the bag on/off techniques employed on the MOVER. The DOE-sponsored document, A Guide to Good Practices at Plutonium Facilities (Pacific Northwest Laboratories, Battelle; PNL-2086, Rev. 1, UC-41; July 1987, p. 3.26) states that, "Bag-out ports, sphincter seals, and airlocks shall be designed and installed to facilitate the introduction and removal of equipment and supplies without compromising contamination control." It is not certain if this document was utilized in the mid-1980's design of the glovebox 
or was incorporated when the glovebox was built in 1996. However, this basic principal appears not to have been effective in the MOVER at LLNL. Table 3 summarizes the comparison of MOVER drum bags and bag-out port to LLNL Plutonium Facility bags and bag port.

Table 3. Comparison of bags, bag port, and bag-changing techniques at the MOVER verses the LLNL Plutonium Facility.

\begin{tabular}{|l|l|l|l|}
\hline \multicolumn{1}{|c|}{ Topic } & \multicolumn{1}{|c|}{ MOVER } & \multicolumn{1}{c|}{$\begin{array}{c}\text { LLNL Plutonium } \\
\text { Facility }\end{array}$} & \multicolumn{1}{c|}{ Comments } \\
\hline $\begin{array}{l}\text { Bag material } \\
\text { and design }\end{array}$ & $\begin{array}{l}\text { Bag is very stiff; extra bag } \\
\text { material causes micro- } \\
\text { channels past sealing } \\
\text { area. Rubber retaining } \\
\text { band appears to not } \\
\text { provide a tight seal of bag } \\
\text { to port. Retaining band } \\
\text { uses 1-in. metal clamp to } \\
\text { join the two ends of } \\
\text { material into a round ring. }\end{array}$ & $\begin{array}{l}\text { Material for bag is pliable } \\
\text { and has minimal extra } \\
\text { material at O-ring to } \\
\text { minimize micro-channels. } \\
\text { Rubber O-ring } \\
\text { (continuous piece of } \\
\text { material) provides a } \\
\text { relatively tight seal to bag } \\
\text { port. }\end{array}$ & $\begin{array}{l}\text { MOVER bag design does } \\
\text { not provide an adequate } \\
\text { seal during operations. }\end{array}$ \\
\hline $\begin{array}{l}\text { Contamination } \\
\text { seal of bag to } \\
\text { port }\end{array}$ & $\begin{array}{l}\text { - Rubber retaining band } \\
\text { - Retaining band } \\
\text { Bungee cord }\end{array}$ & $\begin{array}{l}\text { - Rubber O-ring } \\
\text {-Vinyl tape }\end{array}$ & $\begin{array}{l}\text { MOVER had three sealing } \\
\text { devices to provide a positive } \\
\text { seal of bag to port. All three } \\
\text { are ineffective. }\end{array}$ \\
\hline $\begin{array}{l}\text { Bag-changing } \\
\text { technique }\end{array}$ & $\begin{array}{l}\text { Bags are left on innermost } \\
\text { port ring. }\end{array}$ & $\begin{array}{l}\text { Bags are left at } \\
\text { outermost port ring. }\end{array}$ & $\begin{array}{l}\text { Bags left on innermost port } \\
\text { ring allow contamination to } \\
\text { migrate along the bag ring } \\
\text { that must be cleaned each } \\
\text { time a bag is changed. Bag } \\
\text { changing requires the drum } \\
\text { bag to be first moved to the } \\
\text { outermost port ring. }\end{array}$ \\
\hline
\end{tabular}




\section{Committee Comments}

The IA Committee found no indication of operator error. The CCP personnel who were interviewed demonstrated a good understanding of their work assignments, worked to approved procedures, and performed their assigned tasks in a professional manner. It was evident that the workers were knowledgeable in their safety responsibilities (e.g., PPE use, safety alarms, and evacuation processes) and closely followed the direction of LLNL ES\&H professionals.

The CCP personnel demonstrated pride in the success of the Mobile Vendor program, specifically, the recent processing of more than 400 TRU waste containers at ANL. Their responses emphasized a strong commitment to complete the processing of remaining LLNL waste drums so that the MOVER unit could proceed to its next location (Idaho National Engineering Laboratory) on time and on schedule.

\section{Conclusions and Root Causes}

The event analyzed by the IA Committee was:

The presence of airborne radioactive contamination inside the MOVER when personnel inside the MOVER were out of their respirators, which led to an uptake by the personnel.

The direct cause of the event was:

Release of radioactive contamination from within the Vendor-designed containment envelope created by the glovebox and attached drums and bags.

\section{Conclusions}

The nature of mobile operations established for TRU waste certification to the WIPP can create subtle pressure to limit a probing review that would ensure all questions associated with sitespecific issues are addressed. At present, a large backlog of legacy TRU waste remains to be certified in the DOE complex for shipment to the WIPP. Limited time is available to complete the effort, as established by the EM program, and sites have identified time windows to obtain the services of the Mobile Vendor and equipment. These factors - coupled with direct contractual arrangements between DOE/EM Headquarters (HQ) and CCP to use pre-designed and DOE-approved equipment as well as good operating experiences to date at other sites-tend to inhibit thorough site-specific reviews that could result in a site missing the available operational window.

The intent of the contract was for the CCP contractor to go from site to site in the complex, accept the drums, evaluate or repackage them for WIPP acceptance, certify them for WIPP acceptance, and then return the drums to the site for storage until shipment to the WIPP is accomplished. The contractual relationship implies that the site is using an accepted, complex- 
wide contractor that has well-established design and operations processes. The site is to provide health physics support, analytical and labor support, deliver the waste drums for processing, pick up and store the drums after processing, and then package and load them for shipment to the WIPP. The design and operation of the WIPP Mobile Vendor systems came to LLNL, after operations at other sites, without an approved document 10 CFR 830 Safety Basis and Operational Readiness Review. The documents and reviews were done for the first time at LLNL. For scheduling requirements, the LLNL Documented Safety Analysis/Technical Safety Requirements (DSA/TSRs) were developed before equipment was shipped to LLNL, and the DSA/TSR had to be revised during the process because the Mobile Vendor equipment shipped to LLNL was not exactly the same as that analyzed. The approval authority is DOE/EM HQ. The $\mathrm{CCP}$ contract team was highly confident in the process and operations experience, and looked to the site as a contractor interface for specific support, not to re-evaluate the already-proven subcontract process.

Interviews of CCP employees support this premise. Changes to design or operations-such as adding an external bungee cord on the bag-in/bag-out ports, as recommended by the LLNL HP to address an identified contamination problem - were not viewed by CCP as a necessary design change, but rather as a safety enhancement added to an already acceptable design. A second change, namely, to stop slitting bags of the daughter drums to help control airborne contamination, as one of the final steps in the drum remediation procedure, was not considered to be a procedure change by CCP. Such changes in design and procedures are not reviewed by CCP corporate for their safety implications, but only for their impact on the WIPP waste acceptance criteria. In fact, changes to established design or procedures were generally resisted by CCP.

It is quite possible that this condition (inadequate seal at the bag/drum interface) was present in operations at ANL. However, because the radiological source term in drums at ANL was so much lower than drums with the higher activity drums at LLNL, the airborne concentration remained near or below detectible levels. In addition, the material present as holdup in the MOVER can be very important to transport significant contamination to areas of the box including the bag port. The $\mathrm{Ci}$ content of the drum processed directly prior to the incident was identified as having $27.3 \mathrm{PE} \mathrm{Ci}$. This drum also contained a relatively significant quantity of $\mathrm{Pu}-$ 238, which is very dispersible. Isotopic analysis of the CAM and passive air filters on August 19, 2004, are consistent with the content of the 27.3 PE Ci drum.

The Committee looked at the pre-start review process, including DOE Order $425.1 \mathrm{C}$ and associated guidelines, and concluded that it did not adequately address the design of the glovebox interface from the perspective of design of radiological control. Two independent Operational Readiness Reviews (ORRs) were conducted, one by LLNL and one by DOE. An ORR is a performance-based examination of facilities, equipment, personnel, procedures, and management systems to ensure that a facility is operated safely within its approved safety envelope as defined by the facility safety basis. It is not a process established to analyze the design adequacy of approved individual systems or components. Neither the DOE's requirements for ORRs, nor LLNL guidance on ORRs, require that ORRs analyze the design adequacy of components. In addition, LLNL's ORR apparently did not use HP experts, glovebox 
engineers (system engineers), or glovebox workers with extensive operational experience in LLNL-designed gloveboxes and processing of similar drums at LLNL nuclear facilities.

The IA Committee felt that the manner in which ES\&H support addressed the potential airborne contamination that began to be observed in CAM filters and passive air samplers in April, May, June, July, and August was less than adequate. Beginning in early June 2004, HP 1 who was assigned to the MOVER project began dealing with reports of minor contamination on the drum/glovebox port. This was the same time frame as the CAM alarm that was attributed to radon buildup inside the MOVER, but which was, in fact, caused by airborne contamination. HP 1 brought in as a consultant an HP SME who had previous experience in supporting glovebox operations in B332. The HP incorrectly believed that he understood the cause for the surface contamination events, and that special attention by management was not necessary. The HP communicated frequently with both the H\&ST assigned to the MOVER and Vendor Manager 1 on this issue. However, the HP did not attend the daily pre-operations meetings, which were attended by the RHWM Supervisor 1, Vendor Manager 1, MOVER operators, and the H\&ST. The RHWM Supervisor 1, in turn, had daily informal contact and formal meetings every other week with the RHWM Manager. Given this communication chain, it would appear that regular attendance at the daily project meetings by the HP to discuss issues and monitoring results might have improved communication of issues to RHWM management.

Conditions leading to airborne contamination observed in CAM filters and passive air samplers were not addressed aggressively enough or communicated effectively to Line Management to resolve the gradual or periodic release of airborne contamination prior to the August 19 event. It is possible that effective feedback and reporting mechanisms would have prompted LLNL and CCP line management to intervene and require changes to the process for bag-in/bag-out of highly contaminated drums.

\section{Specific Design and Safety Analysis Issues}

\section{CCP Documents}

A two-volume set MOVER Equipment and Instruments Documental Manual was received by RHWM Supervisor 1 in January 2003.

The manuals contain the following information of specific note:

1. Design drawings clearly that show one CAM sampling at the same location used at LLNL and two fixed air samplers (FAS) at locations similar to those used at LLNL.

2. A MOVER Safety Analysis Document (SAD) dated July 2, 2001. Some examples of what it contains follows: 
The Introduction states:

"The MOVER facility incorporates a variety of safety features designed to protect the operator, technical personnel, the facility where the MOVER is located and the environment. These features provide protection from radiation exposure, radioactive contamination, fire, mechanical hazards, physical hazards, electrical hazards, breathing hazards, and hazardous materials. This document addresses the various hazards and the controls designed to mitigate identified hazards. This SAD is designed to be applicable at any site where the MOVER facility is deployed.

Any changes in operations that do not significantly affect safety or the environment may be approved by the facility manager. The facility manager shall document the change. Any changes that become hazard or safety issues shall have prior approval by the onsite manager and this SAD shall be revised, reviewed and approved before implementing."

Other sections from the SAD:

- Specify (1) CAM and (2) FASs.

- Discuss the use of respirators but only in a generic way.

- Have only one "Holdpoint" that was noted (i.e., contamination limits on drums coming into the MOVER).

- State "Persons performing anything other than administrative work shall wear anti-contamination coveralls, booties, safety glasses, safety shoes and gloves."

3. A Health and Safety Plan-Rev. 5, dated January 2004-was specific to LLNL operations and was reviewed as part of the ORR process.

Section 3.2.3 states,

"TRUtech Team Program Health and Safety Officer ... is responsible for conducting or coordinating health and safety workplace monitoring and/or sampling and analysis, as necessary.

The TRUtech Team Onsite Manager is responsible for evaluating the results of workplace health and safety monitoring and/or analysis and communicating the results to facility managers and TRUtech Team personnel, as appropriate."

\section{LLNL DSA/TSR}

The safety function of the MOVER glovebox is described in the DSA (Section 6.3.4.2.1) as follows: 
"The MOVER glovebox serves as the primary confinement structure to prevent the spread of contamination in the absences of ventilation. By providing a physical barrier from radioactive materials, occupational exposure is minimized."

The glovebox is included in the TSR (Section 6.2) as a passive Safety Significant SSC. Important to the MOVER event is the following administrative control for the glovebox described in Section 5.6.5 of the TSR:

"An initial testing, in-service inspection and test, configuration management, and maintenance program SHALL be established, implemented, and maintained to ensure the integrity of the design features in Section 6."

There are no safety limits or limiting conditions for operations identified as necessary to support the safety analysis.

Effective initial testing of the MOVER glovebox at LLNL was made much more difficult because the glovebox came to LLNL with residual internal contamination from past operations at other sites. In view of that fact, pressure testing the glovebox to evaluate possible leak paths is not considered good radiological-control practice. Furthermore, leak tests of gloveboxes are generally conducted with glove and bag ports closed; therefore, critical bag-to-glovebox sealing mechanisms are not tested. The result is that inspection is the next-best means of complying with the administrative control in the TSR. In lieu of the capability to perform a meaningful glovebox leak test at LLNL, the IA Committee believes that Line Management placed greater reliance on conditions, such as accepted, complex-wide, contractor-established designs and good operating history, as the primary assurance for meeting the DSA/TSR requirements.

\section{Root Causes}

Root causes are the most basic cause(s) that explain why an event happened. They are causes that can reasonably be identified, that senior management has the control to fix, and for which effective recommendations for corrective action(s) to remedy the problem, prevent specific recurrence of the problem, and preclude occurrence of similar problems can be generated. Root causes may arise from a less-than-adequate (LTA) management-system element, which, if corrected, would prevent a recurrence of a similar incident.

To determine the root cause(s) of the MOVER event, the IA Committee reviewed the factual information that it had collected, developed a list of probable causes, and then clarified and removed redundancy in the list. The Committee then determined if the cause was a contributing or root cause using the LLNL Root-Cause MiniMORT (RCMM) process. The RCMM is a form of fault-tree analysis that uses graphic symbols to illustrate the safety program elements that should be a part of every goal-oriented and high-performance management system. The RCMM elements and identified causes were examined and discussed by the IA Committee to determine which elements were LTA on the basis of information gathered by the Committee during the incident analysis. Specifically, the IA Committee looked at causes stemming from errors and 
omissions, inadequacy of physical and administrative barriers, and management systems inadequacy.

The IA Committee concluded that the following root causes led to the MOVER event:

- Root cause 1: LLNL's initial evaluation and formal acceptance testing of the Vendor's confinement system (design, technique, and procedures) were less than adequate. (See $\mathrm{CC} 1, \mathrm{CC} 2$, and CC5.)

- Root cause 2: LLNL's ongoing evaluation of the Vendor's confinement system (design, technique, and procedures) was less than adequate for the bag-in and bag-out operation involving LLNL TRU waste drums. (See CC3, CC4, and CC6.)

\section{Contributing Causes}

Contributing causes (CCs) are events or conditions that, collectively with other causes, increase the likelihood of an event but that individually do not cause the event. The IA committee identified the following CCs for the MOVER event.

\section{CC1}

The CCP/Los Alamos National Laboratory (LANL) initial design of glovebox drum port/bag interface, necessary to maintain the integrity of the seal when working with materials from LLNL drums, was LTA. (See Table 3.) Specific supporting examples are as follows:

- The design of the retaining band was LTA and did not address performance specifications (e.g., torque, change-out frequency) for the band.

- The approach to establishing a seal at the drum ports was ineffective, including use of a retaining clamp on the ends of the internal O-ring of the bags, tape under the exterior retaining band, and lack of taping the end of the bag to the port.

- The design to achieve a wrinkle-free attachment of the bag around the full circumference of the drum port was LTA.

CC2

LLNL's response to NNSA/LSO's ORR comment on the Vendor's configuration management did not fully address the flow down of design intent and specifications, from a radiological control standpoint, to end users at LLNL.

\section{CC3}

The Vendor's (CCP's) safety management of ongoing operations was LTA. Specific supporting examples are as follows:

- Communication to LLNL of previous MOVER operation experiences was not adequate. The full paper trail for exposure histories and airborne monitoring at all sites (NTS, ANL, LANL) where the MOVER had operated was not provided to LLNL by CCP. 
- Changes to operations (addition of the bungee cord) to address emerging issues (low-level airborne contamination) were agreed to by LLNL and CCP Project Managers; however, CCP did not consider these to require procedure or design changes. As a result, these changes were not reviewed by the CCP safety organization. CCP did not seem inquisitive as to the safety implications of change or their need to conduct a safety review of the change. Rather the main concern was if the change impacted the WIPP certification for the drums.

\section{CC4}

Vendor's operational procedures did not include methods for recognizing and responding to changing conditions. Specific supporting examples are as follows:

- The approach and procedure for handling low-Ci and high-Ci drums in the glovebox were the same; consideration of implications of the change in drum activity and material form was LTA.

- Operators normalized events (low-vacuum alarms, elevated meter readings, and minor contaminations) and considered them minor nuisances.

- Identification of radiological hold points for out-of-normal conditions was LTA.

\section{CC5}

LLNL's verification of the Vendor's Quality Assurance Plan for the design and fabrication of the confinement system (design, technique, and procedures) was LTA.

\section{CC6}

Communication of technical issues and operational problems up the LLNL and CCP line management systems was LTA.

\section{Other Comments and Issues}

An Emergency Planning Hazard Assessment (EPHA) has been developed for B696, including the TRU Waste Characterization Segment, because of the hazards associated with the facility. Upset conditions are evaluated, and criteria known as Emergency Action Levels (EALs) are established for off-normal conditions in the facility that could lead to emergencies. The LLNL EAL for Operational Emergencies Not Requiring Further Classification was issued in April 2004 and identifies the following event as one that constitutes and Operational Emergency:

"Any facility evacuation in response to an actual occurrence that requires time-urgent response by specialist personnel, such as hazardous material responders or mutual aid groups not normally assigned to the affected facility."

Post-event communication and notifications through the SEP and LLNL management chain were made as indicated in the Event Timeline (Figure 4). The notified personnel included three qualified LEDOs (the Deputy Department Head for HCD, Deputy Associate Director for SEP, and the on-duty LEDO). Although some judgment is necessary in making determinations as to 
was clear to the trained LEDOs that MOVER event conditions were not met for involving the Duty Fire Chief for classification of an operational emergency. Reasons for this decision include the following:

- Only a portion of the "facility" covered by the EAL was involved; all other portions of the facility did not require evacuation.

- Operators who were involved indicated that there was no accident resulting in a discernable breach of confinement.

- All responses to the event were clearly within the capability of personnel assigned to the facility; no outside resources were needed to respond.

- There were no inactions of radioactive contamination outside the MOVER.

Based on the foregoing, the IA Committee believes that post-event communication and notification were appropriate for the event.

\section{Judgments of Need}

\begin{tabular}{|l|l|l|}
\hline No. & \multicolumn{1}{|c|}{ Judgments of Need } & $\begin{array}{c}\text { Related causal } \\
\text { factors }\end{array}$ \\
\hline JON1 & $\begin{array}{l}\text { LLNL needs to recommend to the Vendor that their design of the seal } \\
\text { between the bag and drum port be redesigned to achieve an effective seal. } \\
\text { This need includes, but is not limited to, recommending that the Vendor } \\
\text { evaluate the current process against other, more-effective interface-seal } \\
\text { processes used in gloveboxes to seal the drum port/bag interface; } \\
\text { modifying their seal process based on their evaluation; and evaluating the } \\
\text { current drum port bags against other drum port bags and providing an } \\
\text { effective drum port/bag interface seal. }\end{array}$ & RC1, CC1 \\
\hline JON2 & $\begin{array}{l}\text { LLNL needs to evaluate and revise, as necessary, its current ORR process } \\
\text { to ensure that the adequacy of a subcontract's design data information and } \\
\text { QA Plan/Program are assessed as part of the ORR process to identify any } \\
\text { gaps in the adequacy of a subcontract's design review for quality- } \\
\text { significant equipment. }\end{array}$ & RC1, CC2, CC5 \\
\hline JON3 & $\begin{array}{l}\text { LLNL needs to review its process for using Vendor-supplied, quality- } \\
\text { significant equipment in a nuclear facility to ensure the equipment is } \\
\text { evaluated either through an LLNL design review or other adequate Vendor } \\
\text { design review. }\end{array}$ & RC1, CC2 \\
\hline JON4 & $\begin{array}{l}\text { LLNL needs to review and revise, as necessary, its processes for formal } \\
\text { communication of the risks associated with Vendor-supplied, quality- } \\
\text { significant equipment that has unverified design reviews to the cognizant } \\
\text { approval authority. }\end{array}$ & $\begin{array}{l}\text { LLNL needs to formally communicate to the Vendor the safety- } \\
\text { management significance and importance of the Vendor providing historic } \\
\text { operational information-involving Vendor-supplied, quality-significant } \\
\text { equipment - to DOE sites prior to the equipment being put to use. }\end{array}$ \\
\hline JON5 & RC2, CC3 \\
\hline
\end{tabular}




\begin{tabular}{|l|l|l|}
\hline JON6 & $\begin{array}{l}\text { LLNL needs to formally communicate to the Vendor the safety- } \\
\text { management significance and importance of the Vendor reviewing site- } \\
\text { proposed process changes involving Vendor-supplied, quality-significant } \\
\text { equipment for safety impacts relative to the initial design specifications and } \\
\text { radiological control intent. }\end{array}$ & RC2, CC3 \\
\hline JON7 & $\begin{array}{l}\text { LLNL needs to review and revise, as necessary, its current procedure- } \\
\text { review processes (contained in the ES\&H Manual), to ensure that hold- } \\
\text { points are assessed for their appropriateness and incorporated into } \\
\text { procedures to proactively prevent out-of-control conditions from occurring, } \\
\text { to allow management adequate time to evaluate areas of concern, and to } \\
\text { render effective decisions to address the concerns. }\end{array}$ & RC2, CC4 \\
\hline JON8 & $\begin{array}{l}\text { LLNL needs to issue an LLNL Lessons Learned document on the } \\
\text { importance and process for effectively communicating technical issues, } \\
\text { operational problems, safety concerns, and off-normal conditions to line } \\
\text { management in a timely manner. }\end{array}$ & RC2, CC6 \\
\hline JON9 & $\begin{array}{l}\text { LLNL needs to develop for submittal to DOE, a Lessons Learned } \\
\text { document on the issues identified in this Incident Analysis Report. }\end{array}$ & \\
\hline
\end{tabular}




\section{Appendix A}

\section{Facility Description}

The TWLP activities were being conducted in two temporary locations in the DWTF, west of Building 695 (B695) and the Building 696 Solid Waste Processing Area (B696S) (see Figure 2). The DWTF is located in the northeast corner of the LLNL site. The entire DWTF complex is surrounded by chain-link fence with locked gates, accessible only to authorized personnel. The TRUW Segments are partitioned from the B695 Segment of the DWTF (a Hazard Category 3 Nuclear facility) for the sole purpose of the project and will be returned to the B695 Segment after the project is complete.

The two segments used for the project, TRU Waste Characterization and TRUPACT-II Loading, are separated by a 36-ft wide "Keep Clear" zone that is used by vehicle traffic incidental to moving waste within, into, and out of the DWTF complex. Vehicles enter and exit through normally closed and locked gates, and obey the $15 \mathrm{mph}$ speed limit within the yard.

The electrical utility yard contains transformers, switchgear, and an emergency diesel generator for B695. B695 is a waste-treatment facility primarily treating radioactively contaminated, aqueous waste. B696S is used primarily to manage solid radioactive waste.

\section{TRU Waste Characterization Segment}

The mobile characterization units are located in a new segment west of B695 and south of the truck scale in the DWTF complex, as shown in Figure 2. Figure 2 also shows the TRU Waste Characterization Segment and the locations of each of the characterization units, including the MOVER. The small storage shed shown to the south of the units contains miscellaneous equipment and does not contain hazardous materials.

\section{Processes and Operations}

The following TRU waste characterization activities were performed by the Central Characterization Project (CCP) mobile characterization units at LLNL:

- Nondestructive examination in the Real-Time Radiography System Number II (RTR-II) unit.

- Nondestructive assay in the High-Efficiency Passive Neutron Counter (HENC) unit.

- Headspace gas sampling (HSGS) and analysis in the Headspace Gas Sampling System Number II (HSGS-II) unit.

- Visual examination and repackaging in the Mobile Visual Examination and Repackaging (MOVER) unit. 
No requirements were established for characterizing drums in a set order. For certifiable waste, drums would be typically moved through the RTR-II, HENC, and HSGS-II units prior to conducting a visual examination of the contents in the MOVER. However, if a problem drum was being remediated, the drum could go to the MOVER at any time. After repackaging to remediate a problem, the drum would likely go back through the other characterization units.

The four characterization units were located in the TRU Waste Characterization Segment. Evacuation warning systems were installed in the TRU Waste Characterization Segment, and actuated by the LLNL fire dispatch system; however, the CAM within the MOVER was not tied into the fire dispatch system.

TRUPACT-II loading was performed in the TRUPACT-II Loading Segment using WIPPsupplied TRUPACT-II casks and vehicles.

\section{Mobile Visual Examination and Repackaging (MOVER) Unit}

The MOVER unit contains a glovebox housed in a mobile, 40 -ft-long transportainer that is transported by a DOE contractor to various DOE sites to visually examine the contents of TRU waste drums. The MOVER unit is a certified DOT 7A Type-A Container. Only one TRU waste drum at a time is brought inside the MOVER unit for characterization. TRU waste drum contents are bagged into the glovebox and opened. The contents are examined and then bagged out into another drum(s). If items are encountered that are safety concerns, the process is halted pending further evaluation to mitigate any potential hazards. Nonconformance items are identified and bagged out into a third drum. The empty discharge ("parent") drum and newly filled drum(s) are then removed from the MOVER unit. Generally, only one drum a day is processed through the glovebox operations in a normal working shift of 8 hours. Operations in the MOVER were intended to meet the controls found in the Document 20.4, "LLNL Occupational Radiation Protection ALARA Program," in the ES\&H Manual.

\section{MOVER Unit Structure}

Figure 3 shows the layout of the MOVER unit. The MOVER structure is classified as a Type II (000) structure per NFPA 220, Standard on Types of Building Construction. Interior walls were constructed as double-walled for contamination purposes, with sealed and polished stainlesssteel interior for ease of decontamination. The MOVER can be transported on public roads without special escort. The outside walls of the MOVER are constructed of carbon steel. The walls are insulated with cellulose, which is manufactured under Consumer Product Safety Commission performance criteria mandating fire standards. The insulation has a flame spread rate of 20 and smoke development rate of 5. Acceptable levels for a Class 1, flame spread rate are less than 25. The interior and exterior of the MOVER are nonflammable metal with steel stud construction. All electrical systems were designed to the National Electrical Code. 


\section{Physical Dimensions}

Physical parameters of the MOVER unit are as follows:

- Length: $40 \mathrm{ft}$.

- Width: 102 in.

- Height: $10 \mathrm{ft}$.

- Gross weight: $34,000 \mathrm{lb}$.

\section{Major Unit Components}

The MOVER includes the following major components:

- MOVER (DOT 7A container).

- Glovebox/Drum Lifter.

- High-efficiency particulate air (HEPA) ventilation system.

\section{MOVER Zones}

There are three zones within the MOVER:

- Zone 1: glovebox.

- Zone 2: Glovebox Operation Room.

- Zone 3: Drum Entry Room (Zone 3A) and Control Room (Zone 3B).

Zone 3 consists of the Drum Entry Room (Zone 3A) at one end of the MOVER, and the Control Room (Zone 3B) at the front or opposite end of the MOVER. Zone 3 provides space for personnel entry, a portal radiation monitor, and system controls. The Glovebox Operation Room (Zone 2), located in the middle of the trailer, is the working area around the Glovebox (Zone 1), which is located in this room. The Glovebox Operation Room (Zone 2) contains the glovebox, drum lifter, HEPA filters, and differential pressure-monitor panel.

The Drum Entry Room is located at one end of the trailer. This room provides space for four standard 55-gallon drums on transport dollies. Typically, only one drum is characterized in this process and placed in the airlock for testing each day.

Doors between each section isolate each room. Doors are kept closed during glovebox operations to maintain negative pressure in the unit. Airflow direction is maintained so that air flows from areas of low contamination to areas of potentially higher contamination before being exhausted through the HEPA ventilation system.

Exterior doors are provided at each end of the trailer. A flashing light next to the exterior doors to the MOVER is lit if the CAM alarms. Exterior doors have a locking handle that can be locked when the MOVER is unattended. Radiological and Warning Postings signs are provided at each door entrance point in accordance with the ES\&H Manual. 
Once operators unlock the exterior doors (i.e., one at the Drum Entry Room end and the other at the Control Room), the keys are removed and controlled by the operator. This procedure precludes locking the doors while operations are ongoing.

\section{Glovebox}

The glovebox is $12 \mathrm{ft}$ long and $2.75 \mathrm{ft}$ high. The end is $2.3 \mathrm{ft}$ wide at the top, tapering out for the height of the windows to $3 \mathrm{ft}$ and then straight down. The volume of the glovebox is about $90 \mathrm{ft}^{3}$. The HEPA ventilation system allows for more than 16 air changes per hour, and it is adjusted to maintain a minimum 25-cfm airflow through the glovebox. The blower system has the capability of keeping 125-fpm face velocity when the glovebox is compromised, and it has twice the airflow capability used under normal conditions. A credible event is the loss of a rubber glove, which would require about $44 \mathrm{cfm}$ through the glove port. Ionizing radiation exposure could be caused by materials undergoing visual examination (VE) and repackaging, which contain waste contaminated with TRU radionuclides. Because VE is a physical process in which waste is handled, extremity exposures are typically the highest. The glovebox enclosure provides complete protection from alpha-radiation exposure. Lead-lined neoprene gloves are used, providing substantial dose reduction to gamma radiation.

The glovebox height must allow for installation of a 55-gallon drum under the glovebox, thereby requiring the glovebox glove ports and working area to be over the normal person's height. Working platforms are positioned on each side of the glovebox and are approximately 16 in. above the floor level. One step is required to access the working platforms. The platforms are hinged to the outside wall of the 7A Container and remain in the up position until used. In the down position, the platforms rest on pieces of angle iron welded to the glovebox feet (upright legs). Drums of characterized waste must be moved into and out from under the glovebox, by lifting the section of the platform in the travel path of the drum. Each liftable section of the platform weighs less than $50 \mathrm{lb}$.

The glovebox frame is fabricated from type-304L stainless steel, as specified on the procurement drawings. The shell material is 0.187-in. sheet stock with a No. 2B mill finish on both sides conforming to ASTM A-240, Standard Specification for Chromium and Chromium-Nickel Stainless Steel Plate, Sheet, and Strip for Pressure Vessels and for General Applications, and A480, Standard Specification for General Requirements for Flat-Rolled Stainless and HeatResisting Steel Plate, Sheet, and Strip. Plate stock is the same grade of stainless steel as the shell material per ASTM A-240. Bars and shapes used in the glovebox component fabrication are the same grade of stainless steel as the glovebox component shell material and meet the requirements of ASTM A-276, Standard Specification for Stainless Steel Bars and Shapes. Forgings, couplings, and other forged pieces used in glovebox component are fabricated of the same grade of stainless steel as the glovebox component shell material. All forgings meet the requirements of ASTM A-182, Standard Specification for Forged or Rolled Alloy-Steel Pipe Flanges, Forged Fittings, and Valves and Parts for High-Temperature Service, or ASTM A-479, Standard Specification for Stainless Steel Bars and Shapes for Use in Boilers and Other Pressure Vessels. Welded studs to the glovebox components are made of 304 series stainless steel. Nuts 
and washers are 300 series stainless steel, unless others are specified by the procurement drawings. The windows of the glovebox are shatter-resistant glass.

\section{Drum Lifter}

The 55-gallon TRU waste drums must be lifted and tilted to a horizontal position to a height of $5 \mathrm{ft}$ from the floor, or $3.5 \mathrm{ft}$ from the worker platform, to be loaded into the glovebox. The worker platform extends $3 \mathrm{ft}$ to the right [as shown in Figure 2-5 of the TRUW Segments DSA (LLNL, 2003c)] of the glovebox. The drum lift is approximately 36 in. wide.

The drum lifter is used to load a TRU waste drum into the glovebox. The working load limit is $500 \mathrm{lb}$. Proof load is 2.5 times the Working Load Performance requirements. The Ultimate Load is 5 times the working load limit. The drum lift meets the performance requirements of Federal Specification FF-T-971b, Type 1, Form 1-Class 8, and ASTM F-1145, Standard Specification for Turnbuckles, Swaged, Welded, Forged. Although the WIPP allows drums weighing as much as $1000 \mathrm{lb}$, all TRU waste drums to be characterized in the characterization units weigh less than $500 \mathrm{lb}$, so the 500-lb limit of the drum lifter is not an issue. RHWM administratively manages operations to ensure that no drums heavier than $500 \mathrm{lb}$ are visually examined in the MOVER.

The lifter has limit switches to prevent travel of the drum-lift-carriage assembly beyond a certain point, which could result in damage to equipment and/or personal injury. The limit switches are checked each day to ensure proper operations of the lifter. Plexiglas side guards for the drum lifter are installed on each side of the lifter trolley. The Plexiglas guards against possible pinch points during lifting and positioning.

The drum lift has a winch to lift 55-gallon drums in place at the glovebox. The winch meets or exceeds the requirements contained in ANSI/American Society of Mechanical Engineers (ASME) B30.7b, Base Mounted Drum Hoists. The winch is operated with a 0.25-in. wire rope. Cables used in the drum lift are fabricated to Federal Specification No. RRN 410 and are proof loaded to $1350 \mathrm{lb}$ without deformation or failure.

\section{Glovebox Equipment Airlock}

An equipment airlock is attached to the glovebox to transfer small items into and out of the glovebox. The current, preferred method is to bag items into and out of the glovebox rather than using the airlock to avoid opening the glovebox. The equipment airlock is maintained at negative pressure, which flows into the glovebox. The access door, measuring approximately 12-in. by 12-in., is a gasketed design, which seals the door to the airlock surface. Once items are placed in the airlock, the outside door is closed and secured. Because the glovebox negative airflow causes a vacuum, any airborne contamination from the airlock flows into the glovebox. 


\section{HEPA Filtration System}

\section{Glovebox and Filtration System}

Air for the three rooms in the MOVER enters through inlet air pre-filters mounted on the outside of the MOVER. One inlet is located in the Control Room, one in the Drum Entry Room, and two on the Glovebox Operation Room. A series of room, glovebox inlet, and glovebox outlet HEPA filters feed into a final HEPA filter before the exhaust fan (described in the next section).

Differential air-pressure zones are maintained throughout the unit to ensure that airflow is directed toward the glovebox - from outside, to airlocks, to the Glovebox Operation Room, and then into the glovebox and HEPA ventilation system. All glovebox air is HEPA filtered by the onboard unit before exhausting outside. The HEPA filters are positioned in the Glovebox Operation Room adjacent to the glovebox. The HEPA system is a Flanders Filter bag-in/bag-out housing model.

The glovebox is the primary confinement barrier that prevents the spread of radioactive contamination into the work area. The glovebox is maintained at a negative pressure of at least 0.2 -in. w.g. (this value is low; LLNL uses 0.5 w.g. or greater relative to the glovebox) relative to the Glovebox Operation Room by the HEPA ventilation system, with a minimum flow of $25 \mathrm{cfm}$, which exhausts through the HEPA filters. The ventilation flow dilutes any flammable vapors that may be in the glovebox.

Glovebox inlet air and exhaust filters for the glovebox are located on top of the glovebox. Air from the glovebox goes through three HEPA filters in series before being exhausted to the outside. Glovebox Operation Room air exhausts through the glovebox inlet air filter as well as through three HEPA filters in parallel mounted on the final HEPA filter housing.

This system is the primary barrier against an uncontrolled release of radioactive material. It should be considered as Defense-In-Depth equipment. The MOVER operator maintains a trend of differential pressures and airflow to aid in determining when a HEPA filter needs to be replaced. Glovebox HEPA filters are changed out in accordance with CCP procedures.

The 9 differential pressure gauges and 5 airflow monitors are described in the CCP MOVER startup and shutdown procedure. These pressure and airflow indicators are displayed on a visual readout panel located on the inside wall of the Glovebox Operation Room. The signal is fed to the computer interface that can be monitored in the Control Room or outside the MOVER. Visual alarms located on the readout activate when the differential pressure or airflow falls outside normal operating ranges, as detailed in the CCP procedure. The alarms are checked for proper operation prior to normal daily operations in the MOVER. Low and high alarm points for the differential pressure and airflow meters are listed in Table 2 of the procedure for startup and shutdown of the MOVER. The Committee noted that constant low-vacuum alarms were accepted by CCP as normal. 
Doors connecting each room in the MOVER are wired to the programmable logic controller (PLC) that provides visual alarms to alert personnel when the doors can or cannot be opened. The primary purpose of this system is to maintain zonal pressure negativity to protect personnel and prevent the spread of airborne contamination in the event of a release. The PLC has a manual test switch for the CAM and ventilation alarms. System operability of the alarms is tested each day before normal operations start.

\section{Belt-Driven Blower}

A belt-driven blower positioned outside the DOT 7A Container is connected to the MOVER by a trunk line. The internally placed HEPA filter captures airborne particulate contamination before air exits the HEPA filter, so the trunk line is not required to be fire resistant.

\section{HEPA Filters}

The HEPA filters are 16-in. wide by 16-in. high by 18 -in. long with 4 -in. male threaded nipples on one end. The HEPA filters act as a confinement barrier to prevent the escape of radionuclides into the environment. The HEPA filters meet the test requirements of Document 12.5, "HighEfficiency Particulate Air (HEPA) Filter System Design for LLNL Applications," in the ES\&H Manual.

\section{External Inlet Air Pre-Filters}

The MOVER has four, external, inlet air pre-filters located on the outside wall. Inlets are located as follows:

- One in the Drum Entry Room.

- One in the Control Room.

- Two in the Glovebox Operation Room.

\section{Other Unit Components}

- Heating, ventilating, and air conditioning system (HVAC) system.

- Fire protection system.

- Camera system and monitors.

- CAM alarm system.

- Fixed-head air-sample system.

- Door interlocks.

- Canberra neutron coincidence analyzer.

- Electrical and lighting system.

- Intercom. 


\section{Heating, Ventilating, and Air Conditioning (HVAC) System}

The inside wall of the Glovebox Operation Room houses a stand-alone air conditioning unit that provides heat and cool air to the area. The system is a circulating air system that uses only the air from within the Glovebox Operation Room and Drum Entry Room. It does not draw air from outside the trailer. The inside wall of the Drum Entry Room houses a stand-alone air conditioning unit that provides heat and cool air to the area. Condensation is drained into a container and then later sampled for contamination. The Control Room also has an installed heating and cooling system that supplies air to the Control Room. Both the Drum Entry Room and Control Room have room-to-room filters.

\section{CAM Alarm System}

For the type of work that is performed in the MOVER, requirements for monitoring the breathing air zone are identified in 10 CFR 835.403. A CAM is located in the Glovebox Operation Room to provide an alarm to indicate airborne alpha contamination. The main instrumentation panel for the CAM is located in the Control Room. Passive air samplers are also located above and near both sides of the glovebox in the MOVER where the VE operators perform work. Filters are regularly checked for alpha contamination to ensure proper operation.

The CAM calculates activity arising from particular isotopes. The process uses a 256-channel analyzer and a set of parameters and equations, which accurately measure activity by subtracting counts from other isotopes. The ALPHA-5A-1 archives historical data, checks for alarms, and responds to user commands.

\section{MOVER Operations Process}

Custody of each TRU waste drum is transferred to the VE operator once placed inside the Drum Entry Room. The drum is placed on a drum dolly. The operator moves the TRU waste drum from the Drum Entry Room to the Glovebox Operation Room. The operator positions the drum in front of the lift and closes the Drum Entry door. Once in the Glovebox Operation Room, the drum's retaining bolt is loosened, and the trunk of an oversize plastic bag is attached to the drum at the first supporting ring of the drum using tape. The glovebox trailer is set up with bag-out drums for characterized waste and suspect waste.

The operator connects the TRU waste drum to the drum lift-clamping fixture. The drum is then mechanically lifted (approximately $4 \mathrm{ft}$ ) along the lifter trolley to a horizontal level plane with the glovebox bag-in port. The open end of the trunk is attached to the bag-in port on the glovebox. The end of the drum is then moved forward into the glovebox to allow for the retaining ring and lid to be removed. The operator removes the inner metal lid on the bag-out port, removes the rigid plastic sleeve in the bag-out port, and replaces the inner lid on the bag-out port. 
The waste contents are removed from the TRU waste drum. Acceptable waste is placed in the characterized drum (bag-out drum). Nonconforming items (those unacceptable to the wastereceiving facility) are placed into a suspect waste drum at the bag-out port. The bag-out TRU waste drum of characterized and repackaged waste is then removed from the glovebox area. The bag-in drum is also removed from the glovebox. All drums are swiped prior to removing them from the MOVER to ensure the outside of the drums are below the contamination release criteria. 


\section{Appendix B}

\section{Gross Alpha Measurements from the B695 MOVER Unit}

\begin{tabular}{|c|c|c|c|c|c|}
\hline $\begin{array}{l}\text { Sample } \\
\text { date }\end{array}$ & Result & $\begin{array}{c}2 \text { Sigma } \\
\text { error }\end{array}$ & LOS & Unit & Sample comments \\
\hline $2 / 24 / 04$ & $2.65 \mathrm{E}-16$ & $1.00 \mathrm{E}+03$ & $1.96 \mathrm{E}-15$ & $\mu \mathrm{Ci} / \mathrm{cm}^{3}$ & CAM \\
\hline $3 / 2 / 04$ & $1.53 \mathrm{E}-15$ & $1.00 \mathrm{E}+03$ & $2.18 \mathrm{E}-15$ & $\mu \mathrm{Ci} / \mathrm{cm}^{3}$ & CAM \\
\hline $3 / 9 / 04$ & $2.51 \mathrm{E}-16$ & $1.00 \mathrm{E}+03$ & $2.15 \mathrm{E}-15$ & $\mu \mathrm{Ci} / \mathrm{cm}^{3}$ & CAM \\
\hline $3 / 23 / 04$ & $2.73 \mathrm{E}-16$ & $1.00 \mathrm{E}+03$ & $2.17 \mathrm{E}-15$ & $\mu \mathrm{Ci} / \mathrm{cm}^{3}$ & CAM \\
\hline $4 / 6 / 04$ & $1.20 \mathrm{E}-14$ & $3.83 \mathrm{E}+01$ & $2.16 \mathrm{E}-15$ & $\mu \mathrm{Ci} / \mathrm{cm}^{3}$ & CAM \\
\hline $4 / 13 / 04$ & $4.16 \mathrm{E}-13$ & $6.48 \mathrm{E}+00$ & $2.18 \mathrm{E}-15$ & $\mu \mathrm{Ci} / \mathrm{cm}^{3}$ & CAM \\
\hline $4 / 20 / 04$ & $9.50 \mathrm{E}-13$ & $4.29 \mathrm{E}+00$ & $2.18 \mathrm{E}-15$ & $\mu \mathrm{Ci} / \mathrm{cm}^{3}$ & CAM \\
\hline $4 / 27 / 04$ & $1.18 \mathrm{E}-13$ & $1.22 \mathrm{E}+01$ & $2.18 \mathrm{E}-15$ & $\mu \mathrm{Ci} / \mathrm{cm}^{3}$ & CAM \\
\hline $5 / 4 / 04$ & $3.16 \mathrm{E}-13$ & $7.42 \mathrm{E}+00$ & $2.17 \mathrm{E}-15$ & $\mu \mathrm{Ci} / \mathrm{cm}^{3}$ & CAM \\
\hline $5 / 11 / 04$ & $3.92 \mathrm{E}-13$ & $6.70 \mathrm{E}+00$ & $2.20 \mathrm{E}-15$ & $\mu \mathrm{Ci} / \mathrm{cm}^{3}$ & CAM \\
\hline $5 / 18 / 04$ & $9.02 \mathrm{E}-13$ & $4.74 \mathrm{E}+00$ & $2.53 \mathrm{E}-15$ & $\mu \mathrm{Ci} / \mathrm{cm}^{3}$ & CAM \\
\hline $5 / 24 / 04$ & $1.28 \mathrm{E}-13$ & $1.09 \mathrm{E}+01$ & $1.87 \mathrm{E}-15$ & $\mu \mathrm{Ci} / \mathrm{cm}^{3}$ & CAM \\
\hline $6 / 1 / 04$ & $3.59 \mathrm{E}-13$ & $6.93 \mathrm{E}+00$ & $2.15 \mathrm{E}-15$ & $\mu \mathrm{Ci} / \mathrm{cm}^{3}$ & CAM \\
\hline $6 / 8 / 04$ & $3.40 \mathrm{E}-14$ & $2.26 \mathrm{E}+01$ & $2.16 \mathrm{E}-15$ & $\mu \mathrm{Ci} / \mathrm{cm}^{3}$ & CAM \\
\hline $6 / 15 / 04$ & $4.56 \mathrm{E}-14$ & $1.97 \mathrm{E}+01$ & $2.19 \mathrm{E}-15$ & $\mu \mathrm{Ci} / \mathrm{cm}^{3}$ & CAM \\
\hline $6 / 22 / 04$ & $1.09 \mathrm{E}-13$ & $1.27 \mathrm{E}+01$ & $2.19 \mathrm{E}-15$ & $\mu \mathrm{Ci} / \mathrm{cm}^{3}$ & CAM \\
\hline $6 / 28 / 04$ & $5.19 \mathrm{E}-13$ & $5.43 \mathrm{E}+00$ & $1.91 \mathrm{E}-15$ & $\mu \mathrm{Ci} / \mathrm{cm}^{3}$ & CAM \\
\hline $7 / 6 / 04$ & $3.75 \mathrm{E}-13$ & $6.78 \mathrm{E}+00$ & $2.15 \mathrm{E}-15$ & $\mu \mathrm{Ci} / \mathrm{cm}^{3}$ & CAM \\
\hline $7 / 13 / 04$ & 7.97E-14 & $1.48 \mathrm{E}+01$ & $2.18 \mathrm{E}-15$ & $\mu \mathrm{Ci} / \mathrm{cm}^{3}$ & CAM \\
\hline $7 / 20 / 04$ & $2.82 \mathrm{E}-14$ & $2.39 \mathrm{E}+01$ & $2.11 \mathrm{E}-15$ & $\mu \mathrm{Ci} / \mathrm{cm}^{3}$ & CAM \\
\hline $7 / 27 / 04$ & 1.06E-14 & $3.92 \mathrm{E}+01$ & $2.10 \mathrm{E}-15$ & $\mu \mathrm{Ci} / \mathrm{cm}^{3}$ & CAM \\
\hline $8 / 3 / 04$ & 6.83E-15 & $4.73 \mathrm{E}+01$ & $1.86 \mathrm{E}-15$ & $\mu \mathrm{Ci} / \mathrm{cm}^{3}$ & CAM \\
\hline $8 / 11 / 04$ & $1.28 \mathrm{E}-13$ & $1.26 \mathrm{E}+01$ & $2.54 \mathrm{E}-15$ & $\mu \mathrm{Ci} / \mathrm{cm}^{3}$ & CAM \\
\hline $8 / 17 / 04$ & $3.17 \mathrm{E}-12$ & $4.22 \mathrm{E}+00$ & $7.75 \mathrm{E}-15$ & $\mu \mathrm{Ci} / \mathrm{cm}^{3}$ & CAM \\
\hline $8 / 19 / 04$ & 4.77E-15 & $7.30 \mathrm{E}+01$ & $3.02 \mathrm{E}-15$ & $\mu \mathrm{Ci} / \mathrm{cm}^{3}$ & CAM \\
\hline $8 / 24 / 04$ & 1.34E-14 & $5.61 \mathrm{E}+01$ & $5.22 \mathrm{E}-15$ & $\mu \mathrm{Ci} / \mathrm{cm}^{3}$ & CAM \\
\hline $4 / 6 / 04$ & $6.16 \mathrm{E}-14$ & $1.85 \mathrm{E}+01$ & $2.62 \mathrm{E}-15$ & $\mu \mathrm{Ci} / \mathrm{cm}^{3}$ & Sampler on left side of glovebox \\
\hline $4 / 13 / 04$ & $6.04 \mathrm{E}-13$ & $5.93 \mathrm{E}+00$ & $2.65 \mathrm{E}-15$ & $\mu \mathrm{Ci} / \mathrm{cm}^{3}$ & Sampler on left side of glovebox \\
\hline $4 / 20 / 04$ & $9.91 \mathrm{E}-13$ & $4.63 \mathrm{E}+00$ & $2.65 \mathrm{E}-15$ & $\mu \mathrm{Ci} / \mathrm{cm}^{3}$ & Sampler on left side of glovebox \\
\hline $4 / 27 / 04$ & $1.94 \mathrm{E}-13$ & $1.05 \mathrm{E}+01$ & $2.65 \mathrm{E}-15$ & $\mu \mathrm{Ci} / \mathrm{cm}^{3}$ & Sampler on left side of glovebox \\
\hline $5 / 4 / 04$ & $7.41 \mathrm{E}-13$ & $5.36 \mathrm{E}+00$ & $2.65 \mathrm{E}-15$ & $\mu \mathrm{Ci} / \mathrm{cm}^{3}$ & Sampler on left side of glovebox \\
\hline $5 / 11 / 04$ & $1.91 \mathrm{E}-12$ & $3.33 \mathrm{E}+00$ & $2.65 \mathrm{E}-15$ & $\mu \mathrm{Ci} / \mathrm{cm}^{3}$ & Sampler on left side of glovebox \\
\hline $5 / 18 / 04$ & $2.05 \mathrm{E}-12$ & $3.21 \mathrm{E}+00$ & $2.64 \mathrm{E}-15$ & $\mu \mathrm{Ci} / \mathrm{cm}^{3}$ & Sampler on left side of glovebox \\
\hline $5 / 25 / 04$ & $2.89 \mathrm{E}-13$ & $8.50 \mathrm{E}+00$ & $2.61 \mathrm{E}-15$ & $\mu \mathrm{Ci} / \mathrm{cm}^{3}$ & Sampler on left side of glovebox \\
\hline $6 / 1 / 04$ & $2.28 \mathrm{E}-12$ & $3.03 \mathrm{E}+00$ & $2.62 \mathrm{E}-15$ & $\mu \mathrm{Ci} / \mathrm{cm}^{3}$ & Sampler on left side of glovebox \\
\hline $6 / 8 / 04$ & $6.67 \mathrm{E}-14$ & $1.78 \mathrm{E}+01$ & $2.63 \mathrm{E}-15$ & $\mu \mathrm{Ci} / \mathrm{cm}^{3}$ & Sampler on left side of glovebox \\
\hline $6 / 15 / 04$ & $3.52 \mathrm{E}-13$ & $7.80 \mathrm{E}+00$ & $2.67 \mathrm{E}-15$ & $\mu \mathrm{Ci} / \mathrm{cm}^{3}$ & Sampler on left side of glovebox \\
\hline $6 / 22 / 04$ & $2.57 \mathrm{E}-13$ & $9.88 \mathrm{E}+00$ & $3.13 E-15$ & $\mu \mathrm{Ci} / \mathrm{cm}^{3}$ & Sampler on left side of glovebox \\
\hline $6 / 28 / 04$ & $1.40 \mathrm{E}-12$ & $3.63 \mathrm{E}+00$ & $2.31 \mathrm{E}-15$ & $\mu \mathrm{Ci} / \mathrm{cm}^{3}$ & Sampler on left side of glovebox \\
\hline $7 / 6 / 04$ & $1.20 \mathrm{E}-12$ & $4.19 \mathrm{E}+00$ & $2.63 \mathrm{E}-15$ & $\mu \mathrm{Ci} / \mathrm{cm}^{3}$ & Sampler on left side of glovebox \\
\hline
\end{tabular}




\begin{tabular}{|c|c|c|c|c|c|}
\hline $\begin{array}{l}\text { Sample } \\
\text { date }\end{array}$ & Result & $\begin{array}{c}2 \text { Sigma } \\
\text { error }\end{array}$ & LOS & Unit & Sample comments \\
\hline $7 / 13 / 04$ & $6.00 \mathrm{E}-13$ & $5.96 \mathrm{E}+00$ & $2.66 \mathrm{E}-15$ & $\mu \mathrm{Ci} / \mathrm{cm}^{3}$ & Sampler on left side of glovebox \\
\hline $7 / 20 / 04$ & $3.39 \mathrm{E}-13$ & $7.59 \mathrm{E}+00$ & $2.56 \mathrm{E}-15$ & $\mathrm{\mu Ci} / \mathrm{cm}^{3}$ & Sampler on left side of glovebox \\
\hline $7 / 27 / 04$ & $2.66 \mathrm{E}-14$ & $2.72 \mathrm{E}+01$ & $2.55 \mathrm{E}-15$ & $\mu \mathrm{Ci} / \mathrm{cm}^{3}$ & Sampler on left side of glovebox \\
\hline $8 / 3 / 04$ & $1.27 \mathrm{E}-14$ & $3.83 E+01$ & $2.28 \mathrm{E}-15$ & $\mu \mathrm{Ci} / \mathrm{cm}^{3}$ & Sampler on left side of glovebox \\
\hline $8 / 11 / 04$ & $3.65 \mathrm{E}-13$ & $8.23 E+00$ & $3.09 \mathrm{E}-15$ & $\mathrm{\mu Ci} / \mathrm{cm}^{3}$ & Sampler on left side of glovebox \\
\hline $8 / 17 / 04$ & $5.90 \mathrm{E}-12$ & $1.89 \mathrm{E}+00$ & $2.62 \mathrm{E}-15$ & $\mu \mathrm{Ci} / \mathrm{cm}^{3}$ & Sampler on left side of glovebox \\
\hline $8 / 24 / 04$ & $2.14 \mathrm{E}-14$ & $4.93 E+01$ & $6.94 \mathrm{E}-15$ & $\mu \mathrm{Ci} / \mathrm{cm}^{3}$ & Sampler on left side of glovebox \\
\hline $3 / 30 / 04$ & $2.57 \mathrm{E}-15$ & $1.00 \mathrm{E}+03$ & $2.68 \mathrm{E}-15$ & $\mu \mathrm{Ci} / \mathrm{cm}^{3}$ & Sampler on right side of glovebox \\
\hline $4 / 6 / 04$ & $4.83 \mathrm{E}-14$ & $2.09 \mathrm{E}+01$ & $2.62 \mathrm{E}-15$ & $\mu \mathrm{Ci} / \mathrm{cm}^{3}$ & Sampler on right side of glovebox \\
\hline $4 / 13 / 04$ & $5.89 \mathrm{E}-13$ & $6.00 \mathrm{E}+00$ & $2.65 \mathrm{E}-15$ & $\mu \mathrm{Ci} / \mathrm{cm}^{3}$ & Sampler on right side of glovebox \\
\hline $4 / 20 / 04$ & $1.71 \mathrm{E}-12$ & $3.52 \mathrm{E}+00$ & $2.65 \mathrm{E}-15$ & $\mu \mathrm{Ci} / \mathrm{cm}^{3}$ & Sampler on right side of glovebox \\
\hline $4 / 27 / 04$ & $1.44 \mathrm{E}-13$ & $1.22 \mathrm{E}+01$ & $2.65 \mathrm{E}-15$ & $\mu \mathrm{Ci} / \mathrm{cm}^{3}$ & Sampler on right side of glovebox \\
\hline $5 / 4 / 04$ & $1.23 \mathrm{E}-12$ & $4.16 \mathrm{E}+00$ & $2.65 \mathrm{E}-15$ & $\mu \mathrm{Ci} / \mathrm{cm}^{3}$ & Sampler on right side of glovebox \\
\hline $5 / 11 / 04$ & $7.69 \mathrm{E}-13$ & $5.26 \mathrm{E}+00$ & $2.65 \mathrm{E}-15$ & $\mu \mathrm{Ci} / \mathrm{cm}^{3}$ & Sampler on right side of glovebox \\
\hline $5 / 18 / 04$ & $1.37 \mathrm{E}-12$ & $3.93 E+00$ & $2.64 \mathrm{E}-15$ & $\mu \mathrm{Ci} / \mathrm{cm}^{3}$ & Sampler on right side of glovebox \\
\hline $5 / 25 / 04$ & $2.15 \mathrm{E}-13$ & $9.86 \mathrm{E}+00$ & $2.61 \mathrm{E}-15$ & $\mathrm{\mu Ci} / \mathrm{cm}^{3}$ & Sampler on right side of glovebox \\
\hline $6 / 1 / 04$ & $7.72 \mathrm{E}-13$ & $5.21 \mathrm{E}+00$ & $2.62 \mathrm{E}-15$ & $\mathrm{\mu Ci} / \mathrm{cm}^{3}$ & Sampler on right side of glovebox \\
\hline $6 / 8 / 04$ & $1.75 \mathrm{E}-13$ & $1.10 \mathrm{E}+01$ & $2.63 \mathrm{E}-15$ & $\mu \mathrm{Ci} / \mathrm{cm}^{3}$ & Sampler on right side of glovebox \\
\hline $6 / 15 / 04$ & 1.13E-13 & $1.38 \mathrm{E}+01$ & $2.67 \mathrm{E}-15$ & $\mu \mathrm{Ci} / \mathrm{cm}^{3}$ & Sampler on right side of glovebox \\
\hline $6 / 22 / 04$ & $1.72 \mathrm{E}-13$ & $1.21 \mathrm{E}+01$ & $3.13 \mathrm{E}-15$ & $\mathrm{\mu Ci} / \mathrm{cm}^{3}$ & Sampler on right side of glovebox \\
\hline $6 / 28 / 04$ & $1.00 \mathrm{E}-12$ & $4.30 \mathrm{E}+00$ & $2.31 \mathrm{E}-15$ & $\mathrm{\mu Ci} / \mathrm{cm}^{3}$ & Sampler on right side of glovebox \\
\hline $7 / 6 / 04$ & $9.84 \mathrm{E}-13$ & $4.63 E+00$ & $2.63 \mathrm{E}-15$ & $\mu \mathrm{Ci} / \mathrm{cm}^{3}$ & Sampler on right side of glovebox \\
\hline $7 / 13 / 04$ & $1.62 \mathrm{E}-13$ & $1.15 \mathrm{E}+01$ & $2.66 \mathrm{E}-15$ & $\mu \mathrm{Ci} / \mathrm{cm}^{3}$ & Sampler on right side of glovebox \\
\hline $7 / 20 / 04$ & $2.19 \mathrm{E}-13$ & $9.45 \mathrm{E}+00$ & $2.56 \mathrm{E}-15$ & $\mu \mathrm{Ci} / \mathrm{cm}^{3}$ & Sampler on right side of glovebox \\
\hline $7 / 27 / 04$ & $2.36 \mathrm{E}-14$ & $2.89 E+01$ & $2.55 \mathrm{E}-15$ & $\mathrm{\mu Ci} / \mathrm{cm}^{3}$ & Sampler on right side of glovebox \\
\hline $8 / 3 / 04$ & 4.13E-14 & $2.11 \mathrm{E}+01$ & $2.28 \mathrm{E}-15$ & $\mu \mathrm{Ci} / \mathrm{cm}^{3}$ & Sampler on right side of glovebox \\
\hline $8 / 11 / 04$ & $2.95 \mathrm{E}-13$ & $9.17 \mathrm{E}+00$ & $3.09 \mathrm{E}-15$ & $\mu \mathrm{Ci} / \mathrm{cm}^{3}$ & Sampler on right side of glovebox \\
\hline $8 / 17 / 04$ & $4.02 \mathrm{E}-12$ & $2.29 \mathrm{E}+00$ & $2.62 \mathrm{E}-15$ & $\mu \mathrm{Ci} / \mathrm{cm}^{3}$ & Sampler on right side of glovebox \\
\hline $8 / 24 / 04$ & $2.84 \mathrm{E}-14$ & $4.16 \mathrm{E}+01$ & $6.15 \mathrm{E}-15$ & $\mu \mathrm{Ci} / \mathrm{cm}^{3}$ & Sampler on right side of glovebox \\
\hline $7 / 27 / 04$ & $2.36 \mathrm{E}-14$ & $2.89 E+01$ & $2.55 \mathrm{E}-15$ & $\mu \mathrm{Ci} / \mathrm{cm}^{3}$ & Sampler on right side of glovebox \\
\hline $8 / 3 / 04$ & $4.13 \mathrm{E}-14$ & $2.11 \mathrm{E}+01$ & $2.28 \mathrm{E}-15$ & $\mathrm{\mu Ci} / \mathrm{cm}^{3}$ & Sampler on right side of glovebox \\
\hline $8 / 11 / 04$ & $2.95 \mathrm{E}-13$ & $9.17 \mathrm{E}+00$ & $3.09 \mathrm{E}-15$ & $\mu \mathrm{Ci} / \mathrm{cm}^{3}$ & Sampler on right side of glovebox \\
\hline $8 / 17 / 04$ & $4.02 \mathrm{E}-12$ & $2.29 \mathrm{E}+00$ & $2.62 \mathrm{E}-15$ & $\mu \mathrm{Ci} / \mathrm{cm}^{3}$ & Sampler on right side of glovebox \\
\hline $8 / 24 / 04$ & $2.84 \mathrm{E}-14$ & $4.16 \mathrm{E}+01$ & $6.15 \mathrm{E}-15$ & $\mathrm{\mu Ci} / \mathrm{cm}^{3}$ & Sampler on right side of glovebox \\
\hline
\end{tabular}




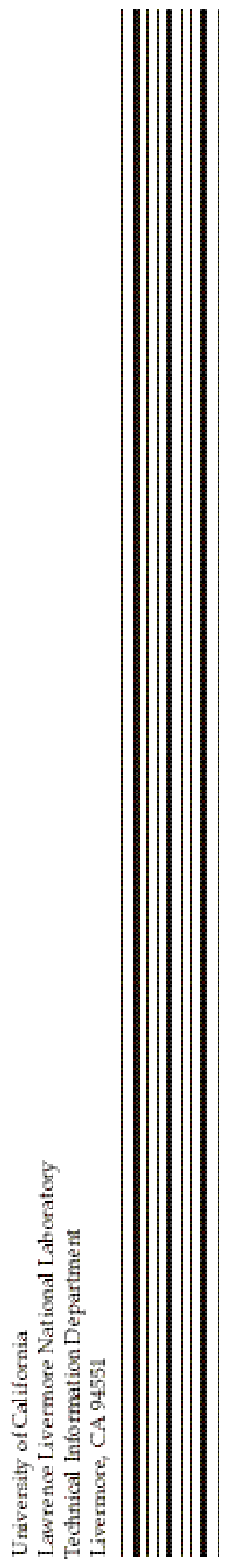

